\title{
From perception to action: Intracortical recordings reveal cortical gradients of human exogenous attention
}

Human exogenous attention relies on a cortical gradient of neural activity extending from perception to action

Tal Seidel Malkinson*1, Dimitri J. Bayle ${ }^{2}$, Alexia Bourgeois ${ }^{3}$, Katia Lehongre ${ }^{4}$, Sara Fernandez-Vidal ${ }^{4}$, Vincent Navarro $^{1,5,6}$, Claude Adam ${ }^{1,5,6}$, Virginie Lambrecq ${ }^{1,5,6}$, Daniel S. Margulies ${ }^{7}$, Jacobo D. Sitt ${ }^{1}$, and Paolo Bartolomeo ${ }^{1}$

\footnotetext{
${ }^{1}$ Sorbonne Université, Inserm UMRS 1127, CNRS UMR 7225, Paris Brain Institute, ICM, Hôpital de la Pitié-Salpêtrière ; 75013 Paris, France

${ }^{2}$ Centre de Recherche sur le Sport et le Mouvement (CeRSM, EA 2931), Université Paris Ouest-La Défense ; 92000 Nanterre, France

${ }^{3}$ Laboratory of Cognitive Neurorehabilitation, Faculty of Medicine, University of Geneva; 1206 Geneva, Switzerland

${ }^{4}$ CENIR - Centre de Neuro-Imagerie de Recherche, Paris Brain Institute, ICM, Hôpital de la Pitié-Salpêtrière ; 75013 Paris, France

${ }^{5}$ Service de neurologie 1, Hôpital de la Pitié-Salpêtrière ; 75013 Paris, France

${ }^{6}$ Service de Neurophysiologie Clinique, Hôpital de la Pitié-Salpêtrière ; F-75013, Paris, France

${ }^{7}$ Laboratoire INCC, équipe Perception, Action, Cognition, Université de Paris ; 75005 Paris, France

* Corresponding author. Email: tal.seidel@mail.huji.ac.il
}

ABSTRACT. Exogenous attention, the process that makes external salient stimuli pop-out of a visual scene, is essential for survival. How attention-capturing events modulate processing dynamics in the human brain remains elusive. We obtained a comprehensive depiction of attentional cortical dynamics at high spatiotemporal resolution, by analyzing brain activity from 1,403 intracortical contacts implanted in 28 individuals, while they performed an exogenous attention task. The timing, location and task-relevance of attentional events defined a spatiotemporal continuum of three neural clusters, which mapped onto cortical core-periphery gradients. Attentional effects emerged at the gradient center, where neural activity reflected both visual input and motor output. These results reveal how large-scale neural ensembles, embedded in the cortical hierarchy, underlie the psychological construct of exogenous attention in the human brain.

When searching for a friend in a crowded public space, it helps if they wave. In such a situation, movement automatically renders them more salient in the visual scene through a fast and dynamic orientation process known as exogenous attention. This fundamental process is prevalent among many vertebrate species (13 ), yet the expansion of attention systems in the human brain sets us apart (4). Despite decades of research, the nature and neural basis of human exogenous attention remain elusive (5). For instance, it is unclear how the timing of attentional events modulates processing dynamics. Specifically, when successive visual events, such as an attentional cue (the hand-wave) followed by a target (the friend's face), appear at the same spatial location with short delays, the cue tends to accelerate target detection, resulting in shorter response times ( $R T$ facilitation). Slightly longer delays, however, slow down target detection, a phenomenon termed inhibition of return (IOR), which may promote spatial exploration $(6,7)$. Human and primate studies revealed that various brain areas contribute to these effects, such as the superior colliculi, the frontal eye fields (FEF), the posterior parietal cortex, and their connections (8-17). For example, damage to these regions in the right hemisphere (18) causes spatial neglect, a condition characterized by 
a failure to orient attention to left-sided events and persistent RT facilitation instead of the typical IOR for right-sided targets $(15,16)$, linking abnormal exogenous attention to this severe neurological disability. Yet, the methods used so far lacked sufficient spatiotemporal resolution to capture rapid attentional dynamics (e.g., human surface electroencephalography (EEG) and functional neuroimaging), or focused on isolated regions in non-human primate electrophysiology, resulting in a piecemeal and fragmented picture. Here we used intracortical EEG (iEEG), a technique with unmatched spatiotemporal resolution in humans (19), to uncover the cortical dynamics of the mechanisms involved in the exogenous orienting of spatial attention. Using data acquired across 28 patients to achieve comprehensive cortical coverage, we provide a fine-grained and integrative depiction of the neural dynamics of exogenous attention.

Twenty-eight participants undergoing presurgical evaluation of their epilepsy with iEEG (age $31.7 \pm 8.1$ years, 15 women, Table 1) performed the Posner peripheral cueing task (7) (Fig. 1A). Participants were asked to detect the appearance of a target within a right-sided or a left-sided placeholder as quickly as possible. A non-predictive peripheral cue preceded the target with two possible stimulus onset asynchronies (SOA): 150ms (short-SOA), or 600ms (long-SOA), and appeared either on the same side of the target (Congruent trials) or opposite side (Incongruent trials) with equal probability. Patients' performance was neurotypical $(6,7)$, with a 30-ms IOR effect (Fig. 1B; 2-way-ANOVA: SOA $\times$ Congruence interaction, $F_{(1,27)}=39.50, p<0.001, \eta^{2}=0.164$; post-hoc test: long-SOA congruent vs. Incongruent $\left.p<0.001\right)$. Congruent and incongruent RTs differed between SOAs (post-hoc tests: $p=0.047$ and $p=0.008$, respectively), but facilitation at short-SOA failed to reach significance ( $p=0.37$; see Fig. S1 for individual RTs and target-side analysis), as is often the case with this delicate effect (20).

High-frequency broadband power (55-145Hz; HFBB) was extracted from 1,403 usable contacts with bipolar montage, pooled across all participants (Fig. 1C; See Table 2 for detailed localization). Target-locked mean normalized HFBB activity was computed for each contact in the eight experimental conditions $(2 \times 2 \times 2$ design: SOA x Congruence $x$ Ipsilateral/Contralateral target relative to contact; Fig. 1C).

In order to reveal the main temporal patterns of activity that were sensitive to the experimental manipulations, we used a data-driven clustering approach (Fig. S2), which we applied to 664 responsive contacts (with at least 100ms-long significant effect in one condition or more, compared to baseline). We calculated the temporal trajectory in the 8-dimensional condition space (Congruent / Incongruent Trial X short-SOA / long-SOA X Ipsilateral / contralateral target) for each of the responsive contacts, i.e. the path of each contact's HFBB over time across all experimental conditions. Using k-means clustering, each trajectory was then assigned to the cluster with the nearest trajectory-centroid, by iteratively minimizing within-cluster Manhattan distances. For further analyses, we used a $k=6$ solution, chosen using the Elbow method (see Fig. S2C and Fig. S7 for cluster number and stability).

Out of the chosen 6-cluster solution (Fig. S2A-C), we focused on three clusters of contacts whose activity patterns changed across the experimental conditions (Fig. 1D, Fig. S8). The first cluster (Early cluster; 68 contacts from 12 patients; Fig. 1D right) showed early responses only to contralateral cues and targets, and mainly consisted of contacts in the bilateral occipitotemporal cortex and in the prefrontal cortex, around the FEF (Fig. 1E top). A second cluster (Middle cluster; 97 contacts from 18 patients; Fig. 1D middle) showed later ipsilateral and contralateral responses, with stronger responses to contralateral stimuli. Most contacts were in the caudal portion of the TPJ, around the angular gyrus, posterior temporal cortex and prefrontal cortex (Fig. 1E middle). The cluster was lateralized to the right hemisphere (Fig. S2D-E). The third cluster (L cluster; 67 contacts from 16 patients; Fig. 1D left) was the last to react, with stronger responses to bilateral targets than to cues. It was located mainly in the rostral TPJ region (around the supramarginal gyrus), 
posterior temporal cortex and prefrontal cortex (Fig. 1E bottom), and was lateralized to the left hemisphere (Fig. S2 D-E). Importantly, the response in the Middle and the Late clusters was sensitive to the cue-target delay. For the short-SOA, cue and target responses summed together, but they were segregated for the long-SOA. Activity in the three remaining clusters did not seem to vary across experimental conditions, with one cluster showing late inhibition, one showing late activation and one showing no response (see Fig. S2 and S8).

We next explored how our experimental manipulation of attentional events influenced the clusters' neural activity. Specifically, we examined IOR-related activity, by comparing long-SOA Congruent and Incongruent trials (time-resolved 3-way ANOVA; Fig. 2). The Middle cluster showed a Congruence effect at the offset of the target-related activity (240-300ms post target; all $p<0.002$; see Fig. 2D for examples of single contacts). Moreover, in the contacts of this cluster in the right hemisphere, the response peaked $22 \mathrm{~ms}$ later in the Congruent than in the Incongruent trials (140-220ms post target onset; Hemisphere $x$ Congruence interaction: all $p<0.03$; post hoc tests: all $p<0.014)$, mirroring behavioral IOR. There were no congruence effects in the Early cluster (Fig. 2A) and in the Late cluster there was only a late Congruence effect at 660680 ms post-target (all $p<0.003$ ). Therefore, IOR-related activity was mainly restricted to the Middle cluster, thus attentional events corresponded to the neural dynamics of this cluster.

How do these clusters of neural activity relate to behavior? We examined whether cluster neural dynamics relate to motor response timing, across experimental conditions. In each cluster, we divided the trials (pooled across conditions) into 20 quantiles according to their RT (Fig. 3A), and tested the relation of RTbins with the neural activity using a time-resolved 1-way repeated measures ANOVA (See Fig. 3B-C for results and examples of single contacts). In the Middle cluster, the offset of the target-related activity differed across RT bins (300-560ms post target; all $p<0.028$ ), with a faster decay at faster RT-bins, just before the motor response. In the Late cluster, an RT-bin effect occurred around the peak of target-related activity and button-press time $(280-300$ and $400-420$ ms post target; all $p<0.007)$. In the Early cluster, an RT-bin effect occurred at 500-540 and 560-680ms post target onset $(p<0.002)$, suggesting an RT-related late modulation after response offset and button press time. RT-related target-locked activity in the Middle and Late clusters was confirmed by cross-correlation analysis (Fig. S3), which revealed that only in these clusters, did the temporal dynamics of neural activity shift according to RTs, and that this shift correlated with RTs. Thus, neural activity in the Middle and Late clusters was associated with behavior as measured by response times.

We next adopted a complementary perspective, and examined the visual modulation of response-locked activity. We applied the trajectory k-means clustering analysis to response-locked activity (Fig. S4 A-C). A contingency analysis revealed four clusters of contacts, corresponding to the previously identified targetlocked clusters $\left(X^{2}{ }_{(30)}=1442 ; p<0.001\right.$; Contingency coefficient, 0.83; Fig. 3 and S4D). Specifically, analysis of response-locked activity disentangled early and late activity clusters: an RT-Early cluster (46 contacts; $60.3 \%$ of Early target-locked cluster), an RT-Middle1 cluster (85 contacts; $35.3 \%$ of Early and $49.5 \%$ Middle target-locked clusters), a RT-Middle2 cluster (79 contacts; $46.4 \%$ of Middle and $31.3 \%$ of Late target-locked clusters), and a RT-Late (39 contacts; $50.7 \%$ of the Late target-locked cluster). We repeated the RT-binning analysis, as described above (Fig. 3D), and tested the RT-bin effect on the neural activity using a timeresolved 1-way repeated measures ANOVA (See Fig. 3E-F for results and examples of individual contacts). Because RT is defined as the time from target onset to the response, this procedure sorted the responselocked trials according to target onset, and thus could unveil visual modulation of response-locked activity. The onset of the response-locked activity was modulated by target onset only in the RT-Early (120-100ms 
pre-response; all $p<0.04)$ and the RT-Middle1 clusters $(700-680 \mathrm{~ms}, 520-500 \mathrm{~ms}, 300-200 \mathrm{~ms}$ pre-response; all $p<0.004)$. In the RT-Middle2 and RT-Late clusters, the response-locked activity peak was aligned to the response without significant visual modulation. The visual modulation of response-locked activity in the RTEarly and RT-Middle1 clusters was confirmed by a cross-correlation analysis (Fig. S5), which revealed that only for contralateral targets in these clusters the temporal dynamics of neural activity was shifted according to target-onset and this shift correlated with target-onset time. Thus, response-locked activity revealed that only the clusters with early response-locked activity showed visual modulation, while clusters with later activity were only sensitive to the timing of the motor response.

Finally, we examined the spatiotemporal relationships between the clusters. The three target-locked clusters formed a temporal gradient (an axis of variance in cortical features, along which areas fall in a spatially continuous order; Fig. 4A-B). The first activity cluster was the Early cluster, which peaked around $182 \pm 78 \mathrm{~ms}$ post-target. Then followed the Middle cluster $(262 \pm 75 \mathrm{~ms}$ post-target), and finally the Late cluster (383 $\pm 141 \mathrm{~ms}$ post-target; Mixed Anova: Cluster main effect $F(2,229)=102.7, p<0.001, \eta^{2}=0.378$; linear polynomial contrast: $p \leq 0.001)$. This temporal gradient was mirrored by a topographic core-periphery spatial gradient: a large-scale cortical organization based on the differentiation of connectivity patterns that captures a spatial and functional spectrum from perception and action (periphery) to more abstract cognitive functions (core) (21), akin to Mesulam's (22) unimodal-to-transmodal cortical hierarchy. The position of a cortical region along this gradient reflects its microstructural and genetic features, connectivity profile, and functional role $(23,24)$. Two main components define this gradient: Gradient 1 extends from primary unimodal to transmodal regions, and Gradient 2 separates somatomotor and auditory cortices from visual cortex (21). The Early cluster contacts were the most peripheral and closest to the visual end of Gradient 2; contacts in the Late cluster were the closest to the core, extending from the somatomotor end to transmodal regions (Gradient 1 electrode values: 1-way Anova: $F(2,229)=7.74 ; p<0.001, \eta^{2}=0.06$; linear polynomial contrast: $p \leq 0.001$; Gradient 2 electrode values: 1-way Anova: $F(2,229)=77.79 ; p<0.001$, $\eta^{2}=0.28$; linear polynomial contrast: $p \leq 0.001$; Fig. $\left.4 C-D\right)$. A similar spatiotemporal gradient emerged in the response-locked clusters (Fig. 4E-H). Notably, locking activity to the response allowed separating the peripheral RT-Middle1 contacts from the RT-Middle2 contacts, which were closer to the core. Thus, both target-locked and response-locked clusters can be mapped onto the cortical spatiotemporal gradient.

Here we aimed to resolve how attention-capturing events modulate processing in the human brain and shape our behavior. Overall, we provide a high-resolution, comprehensive depiction of the large-scale cortical dynamics underlying human exogenous attention. Our findings reveal that attentional events differentially define neural activity along a series of clusters, which form a spatiotemporal continuum, extending from the visual cortex to higher frontoparietal regions. Visual input modulated neural activity at one end of the continuum, while on its other end neural activity reflected motor output. Neural attention effects emerged at the center of the continuum, where neural activity reflected both visual input and motor output. Moreover, this perception-attention-response continuum could be mapped onto the peripherycore cortical gradient, which spans sensorimotor and transmodal areas, and is suggested to be a primary organizing axis of the human cerebral cortex (21-23).

We identified three key components along exogenous attention's cortical gradient. The first, the Early cluster, is situated at the peripheral end of the cortical gradient, encompassing the occipito-temporal cortex (25), and the vicinity of the FEFs (26), where ultra-fast visual activation was reported (27). It only responded to contralateral visual stimuli, and its neural responses to the cue and target were segregated, 
even at the short cue-target delay. Conversely, the Middle and Late clusters are located closer to core regions of the cortical gradient, and overlap with known frontoparietal attention networks $(17,28,29)$. Importantly, in the TPJ, a part of the right-lateralized ventral attention network, these clusters occupy distinct portions, which differ in their functional and structural connectivity (30-33). The caudal TPJ portion (the Middle cluster) connects to the superior frontal gyrus/FEF of the dorsal attention network $(30,32,33)$ through the middle branch of the superior longitudinal fasciculus (SLF II), and thus provides direct communication between the ventral and dorsal attention networks. In contrast, the rostral TPJ (the Late cluster) is connected to the middle and inferior frontal gyri through the ventral branch of the SLF (SLF III), thus linking nodes of the ventral attention network. Both SLF II and SLF III show anatomical or functional lateralization to the right hemisphere (30) and their inactivation or disconnection was associated with signs of left spatial neglect $(15,18)$. Notably, cue and target neural responses of the Middle and the Late clusters at the short cue-target delay were integrated in a single peak of activity. However, the activity in these clusters may represent different processing stages. The neural activity in the Middle cluster, occurring midway along the gradient, is sensitive to cue-target spatial positions and delays, and exhibits IOR-related onset and offset. Both visual processing of the target and manual response preparation shape the neural activity in this cluster, which is lateralized to the right hemisphere, consistent with lesion and neurostimulation data on IOR $(10-12,15,16)$. Our results suggest that this cluster's activity represents a key attentional processing stage at the nexus between perception and action. On the other hand, the neural activity in the Late cluster shows sensitivity to stimulus identity, with stronger activation for responserequiring targets than for cues. It is lateralized to the left hemisphere, contralateral to the responding hand, and its response-locked activity peaks at the time of the motor response, which also modulates its targetlocked activity. Furthermore, this cluster is anatomically situated between the somatomotor end and transmodal core regions of the core-periphery gradients. Therefore, the Late cluster may instead encode aspects of the response.

The differential integration of cue and target responses along the attentional neural continuum is consistent with a key feature of the core-periphery gradient: a temporal hierarchy of receptive windows, analogous to the spatial hierarchy of receptive fields (23, 24, 34-38). Moving from peripheral regions such as early visual cortex, to core regions such as the intraparietal sulcus, temporal receptive windows become longer, integrating activity over longer durations, with increasing selectivity for coherent temporal structures $(23,34-36)$. Such hierarchy of temporal scales could serve our dynamical interaction with a continuously changing environment, from fast fluctuations associated with sensory processing at the bottom of the hierarchy, to slow ones at the top, reflecting contextual changes in the environment (35). Recurrent temporal computations along the temporal hierarchy could help to incorporate prior events, by increasing selectivity to temporal patterns and enhancing robustness to noise (36). Indeed, recent evidence (24) showed that neural timescales could change to serve cognitive functions. Specifically, prefrontal cortex timescales expanded during working memory maintenance and predicted individual performance (24). Similarly, our results reveal potential temporal operations at the basis of the psychological concept of exogenous attention. These findings dovetail with the hypothesis that $R T$ facilitation results from a summation of cue-related and target-related responses, thus reflecting hard-wired limitations of the neural system that cannot respond separately to rapidly repeated stimuli, and processes them as a single event $(6,39,40)$. Longer cue-target delays could instead provide the system with enough time to segregate cueand target-related responses $(6,39)$. The integration of cue-target responses in the Middle and the Late clusters in the long-SOA could reflect temporal pooling, i.e. the integration of prior information across the temporal window that makes neural response robust to changes in the precise timing of inputs (36). In the 
Early cluster, situated lower in the hierarchy, temporal receptive windows are shorter, allowing for segregation of activity even at short delays. In upstream frontoparietal clusters where temporal windows are longer, cue- and target-induced responses resulted in a single activity peak. This temporal pooling might group the cue and target in a single event (40), leading to RT facilitation at short cue-target delays (6, 39, 40). As for the phenomenon of IOR, our findings suggest that in the Middle cluster, the timing of response peak and decay may be involved in the generation of IOR, but whether or not these dynamics relate to temporal operations will be investigated in the future. Thus, our study contributes to the understanding of the involvement of temporal operations in cognitive processes.

Our findings support a model of time-resolved segregation and integration of attentional events across a large-scale gradient of cortical processing streams. These neural dynamics are a potential mechanism through which the timing of attentional events shapes neural processing and consequently our behavior, and uncover the fine-grained spatiotemporal characteristics of the neural underpinnings of exogenous attention in the human brain. 


\section{References}

1. L. Zhaoping, From the optic tectum to the primary visual cortex: migration through evolution of the saliency map for exogenous attentional guidance. Curr. Opin. Neurobiol. 40, 94-102 (2016).

2. T. Lev-Ari, Y. Zahar, A. Agarwal, Y. Gutfreund, Behavioral and neuronal study of inhibition of return in barn owls. Sci. Rep. 10, 7267 (2020).

3. S. Gabay, T. Leibovich, A. Ben-Simon, A. Henik, R. Segev, Inhibition of return in the archer fish. Nat. Commun. 4, 1657 (2013).

4. G. H. Patel, D. Yang, E. C. Jamerson, L. H. Snyder, M. Corbetta, V. P. Ferrera, Functional evolution of new and expanded attention networks in humans. Proc. Natl. Acad. Sci. U. S. A. 112, 9454-9459 (2015).

5. J. Lupiáñez, R. M. Klein, P. Bartolomeo, Inhibition of return: Twenty years after. Cogn. Neuropsychol. 23, 1003-1014 (2006).

6. J. Lupiáñez, in Attention and Time, A. C. Nobre, J. T. Coulle, Eds. (Oxford University Press, 2010), pp. $17-34$.

7. M. I. Posner, Y. Cohen, in Attention and performance X: Control of language processes, H. Bouma, D. Bouwhuis, Eds. (Erlbaum, Hillsdale, NJ, 1984), pp. 531-56.

8. K. Mirpour, F. Arcizet, W. S. Ong, J. W. Bisley, Been there, seen that: a neural mechanism for performing efficient visual search. J. Neurophysiol. 102, 3481-3491 (2009).

9. K. Mirpour, Z. Bolandnazar, J. W. Bisley, Neurons in FEF Keep Track of Items That Have Been Previously Fixated in Free Viewing Visual Search. J. Neurosci. 39, 2114-2124 (2019).

10. A. Bourgeois, A. B. Chica, A. Valero-Cabre, P. Bartolomeo, Cortical control of inhibition of return: Causal evidence for task-dependent modulations by dorsal and ventral parietal regions. Cortex. 49, 22292238 (2013).

11. A. Bourgeois, A. B. Chica, A. Valero-Cabre, P. Bartolomeo, Cortical control of Inhibition of Return: Exploring the causal contributions of the left parietal cortex. Cortex. 49, 2927-2934 (2013).

12. T. Ro, A. Farnè, E. Chang, Inhibition of return and the human frontal eye fields. Exp. Brain Res. 150, 290-296 (2003).

13. A. Sapir, N. Soroker, A. Berger, A. Henik, Inhibition of return in spatial attention: direct evidence for collicular generation. Nat. Neurosci. 2, 1053-1054 (1999).

14. M. C. Dorris, R. M. Klein, S. Everling, D. P. Munoz, Contribution of the primate superior colliculus to inhibition of return. J. Cogn. Neurosci. 14, 1256-1263 (2002).

15. A. Bourgeois, A. B. Chica, R. Migliaccio, M. Thiebaut de Schotten, P. Bartolomeo, Cortical control of inhibition of return: evidence from patients with inferior parietal damage and visual neglect. Neuropsychologia. 50, 800-809 (2012).

16. E. Siéroff, C. Decaix, S. Chokron, P. Bartolomeo, Impaired orienting of attention in left unilateral neglect: A componential analysis. Neuropsychology. 21, 94-113 (2007). 
17. M. Corbetta, G. L. Shulman, Control of goal-directed and stimulus-driven attention in the brain. Nat. Rev. Neurosci. 3, 201-215 (2002).

18. M. Thiebaut de Schotten, M. Urbanski, H. Duffau, E. Volle, R. Levy, B. Dubois, P. Bartolomeo, Direct evidence for a parietal-frontal pathway subserving spatial awareness in humans. Science. 309, 2226-2228 (2005).

19. R. Mukamel, I. Fried, Human intracranial recordings and cognitive neuroscience. Annu. Rev. Psychol. 63, 511-537 (2012).

20. A. B. Chica, E. Martín-Arévalo, F. Botta, J. Lupiánez, The Spatial Orienting paradigm: How to design and interpret spatial attention experiments. Neurosci. Biobehav. Rev. 40, 35-51 (2014).

21. D. S. Margulies, S. S. Ghosh, A. Goulas, M. Falkiewicz, J. M. Huntenburg, G. Langs, G. Bezgin, S. B. Eickhoff, F. X. Castellanos, M. Petrides, E. Jefferies, J. Smallwood, Situating the default-mode network along a principal gradient of macroscale cortical organization. Proc. Natl. Acad. Sci. U. S. A. 113, 12574-12579 (2016).

22. M. M. Mesulam, Principles of behavioral and cognitive neurology (Oxford University Press, New York, NY, ed. 2, 2000).

23. J. M. Huntenburg, P.-L. Bazin, D. S. Margulies, Large-Scale Gradients in Human Cortical Organization. Trends Cogn. Sci. 22, 21-31 (2018).

24. R. Gao, R. L. van den Brink, T. Pfeffer, B. Voytek, Neuronal timescales are functionally dynamic and shaped by cortical microarchitecture. Elife. 9 (2020), doi:10.7554/eLife.61277.

25. M. Rosenke, R. van Hoof, J. van den Hurk, K. Grill-Spector, R. Goebel, A Probabilistic Functional Atlas of Human Occipito-Temporal Visual Cortex. Cereb. Cortex. 31, 603-619 (2021).

26. M. Vernet, R. Quentin, L. Chanes, A. Mitsumasu, A. Valero-Cabré, Frontal eye field, where art thou? Anatomy, function, and non-invasive manipulation of frontal regions involved in eye movements and associated cognitive operations. Front. Integr. Neurosci. 8, 66 (2014).

27. H. Kirchner, E. J. Barbeau, S. J. Thorpe, J. Régis, C. Liégeois-Chauvel, Ultra-rapid sensory responses in the human frontal eye field region. J. Neurosci. 29, 7599-7606 (2009).

28. R. F. Helfrich, I. C. Fiebelkorn, S. M. Szczepanski, J. J. Lin, J. Parvizi, R. T. Knight, S. Kastner, Neural Mechanisms of Sustained Attention Are Rhythmic. Neuron. 99, 854-865.e5 (2018).

29. T. J. Buschman, S. Kastner, From Behavior to Neural Dynamics: An Integrated Theory of Attention. Neuron. 88, 127-144 (2015).

30. M. Thiebaut de Schotten, F. Dell'Acqua, S. J. Forkel, A. Simmons, F. Vergani, D. G. M. Murphy, M. Catani, A lateralized brain network for visuospatial attention. Nat. Neurosci. 14, 1245-1246 (2011).

31. R. B. Mars, J. Sallet, U. Schüffelgen, S. Jbabdi, I. Toni, M. F. Rushworth, Connectivity-based subdivisions of the human right "temporoparietal junction area": evidence for different areas participating in different cortical networks. Cereb. Cortex. 22, 1894-1903 (2012). 
32. P. Bartolomeo, T. Seidel Malkinson, Hemispheric lateralization of attention processes in the human brain. Curr Opin Psychol. 29, 90-96 (2019).

33. T. Hattori, K. Ito, C. Nakazawa, Y. Numasawa, M. Watanabe, S. Aoki, H. Mizusawa, S. Ishiai, T. Yokota, Structural connectivity in spatial attention network: reconstruction from left hemispatial neglect. Brain Imaging Behav. 12, 309-323 (2018).

34. U. Hasson, E. Yang, I. Vallines, D. J. Heeger, N. Rubin, A hierarchy of temporal receptive windows in human cortex. J. Neurosci. 28, 2539-2550 (2008).

35. S. J. Kiebel, J. Daunizeau, K. J. Friston, A hierarchy of time-scales and the brain. PLoS Comput. Biol. 4, e1000209 (2008).

36. K. D. Himberger, H.-Y. Chien, C. J. Honey, Principles of Temporal Processing Across the Cortical Hierarchy. Neuroscience. 389, 161-174 (2018).

37. A. Stigliani, B. Jeska, K. Grill-Spector, Encoding model of temporal processing in human visual cortex. Proc. Natl. Acad. Sci. U. S. A. 114, E11047-E11056 (2017).

38. J. Zhou, N. C. Benson, K. N. Kay, J. Winawer, Compressive Temporal Summation in Human Visual Cortex. J. Neurosci. 38, 691-709 (2018).

39. T. Seidel Malkinson, P. Bartolomeo, Fronto-parietal organization for response times in inhibition of return: The FORTIOR model. Cortex. 102, 176-192 (2018).

40. H. M. Krüger, W. J. Maclnnes, A. R. Hunt, Perceptual merging contributes to cueing effects. J. Vis. 14 (2014), doi:10.1167/14.7.13.

41. F. Pérez-García, K. Lehongre, E. Bardinet, P. Jannin, S. Fernandez-Vidal, Automatic Segmentation Of Depth Electrodes Implanted In Epileptic Patients: A Modular Tool Adaptable To Multicentric Protocols. 56 (2015).

42. R. S. Desikan, F. Ségonne, B. Fischl, B. T. Quinn, B. C. Dickerson, D. Blacker, R. L. Buckner, A. M. Dale, R. P. Maguire, B. T. Hyman, M. S. Albert, R. J. Killiany, An automated labeling system for subdividing the human cerebral cortex on MRI scans into gyral based regions of interest. Neuroimage. 31, 968-980 (2006).

43. Team, Jasp, JASP (Version 0.14.1)[Computer software] (2020).

44. R. Oostenveld, P. Fries, E. Maris, J.-M. Schoffelen, FieldTrip: Open source software for advanced analysis of MEG, EEG, and invasive electrophysiological data. Comput. Intell. Neurosci. 2011, 156869 (2011).

45. S. Ray, J. H. R. Maunsell, Different origins of gamma rhythm and high-gamma activity in macaque visual cortex. PLoS Biol. 9, e1000610 (2011).

46. R. F. Helfrich, R. T. Knight, in Handbook of Clinical Neurology, M. D'Esposito, J. H. Grafman, Eds. (Elsevier, 2019), vol. 163, pp. 35-59.

47. O. Jensen, J. Kaiser, J.-P. Lachaux, Human gamma-frequency oscillations associated with attention and memory. Trends Neurosci. 30, 317-324 (2007).

48. T. M. Kodinariya, P. R. Makwana, Review on determining number of Cluster in K-Means Clustering. Aquat. Microb. Ecol. 1, 90-95 (2013). 
bioRxiv preprint doi: https://doi.org/10.1101/2021.01.02.425103; this version posted April 6, 2021. The copyright holder for this preprint (which was not certified by peer review) is the author/funder, who has granted bioRxiv a license to display the preprint in perpetuity. It is made available under aCC-BY-ND 4.0 International license.

49. K. J. Friston, J. T. Ashburner, S. J. Kiebel, T. E. Nichols, W. D. Penny, Statistical parametric mapping: The analysis of functional brain images: The analysis of functional brain images (Academic Press, 2010). 
Acknowledgments: We would like to thank Pietro Avanzini, Danilo Bzdok, Florence Bouhali, and the PICNIC lab at the ICM for invaluable discussions and assistance.

\section{Funding:}

Israel Science Foundation postdoctoral fellowship number 57/15 (TSM)

Marie Sklodowska Curie fellowship 702577-DynamAtt (TSM)

Agence Nationale de la Recherche BRANDY grant ANR-16-CE37-0005 (TSM, DJB, VN, SFV, PB)

Author contributions:

Conceptualization: TSM, DJB, PB

Data curation: KL

Formal analysis: TSM

Methodology: TSM, JDS

Investigation: TSM, DJB

Visualization: TSM

Funding acquisition: TSM, PB

Project administration: TSM

Resources: KL, SFV, VN, CA, VL, DSM

Software: TSM, DJB, AB, JDS, SFV, DSM

Supervision: $\mathrm{PB}$

Writing - original draft: TSM

Writing - review \& editing: TSM, DJB, AB, KL, SFV, VN, CA, VL, DSM, JDS, PB

Competing interests: Authors declare that they have no competing interests.

\section{Supplementary Materials}

Materials and Methods

Figs. S1 to S8

Table S1

References (41-49)

Movies S1 to S2 
bioRxiv preprint doi: https://doi.org/10.1101/2021.01.02.425103; this version posted April 6, 2021. The copyright holder for this preprint (which was not certified by peer review) is the author/funder, who has granted bioRxiv a license to display the preprint in perpetuity. It is made available under aCC-BY-ND 4.0 International license.
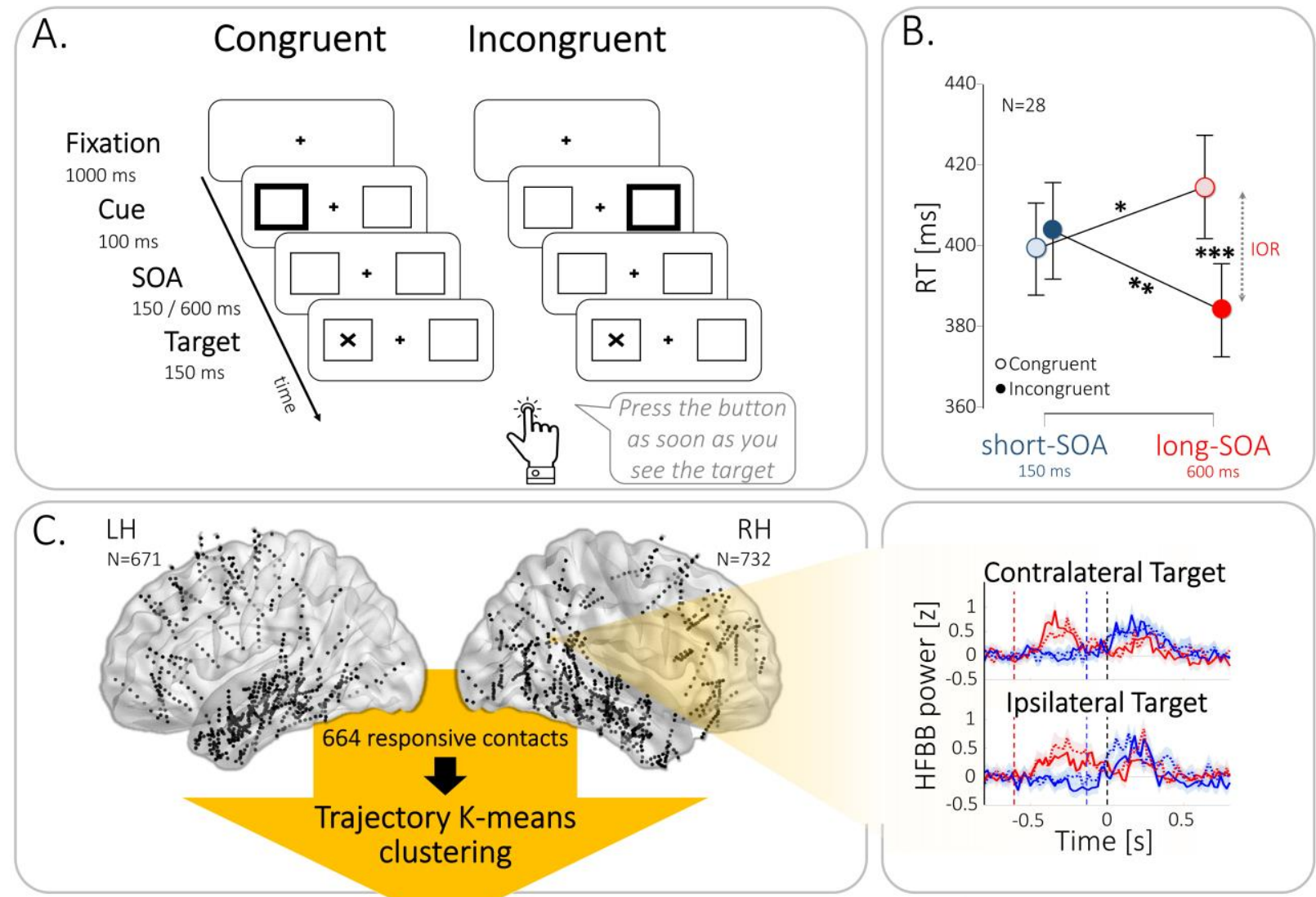

\section{RH}
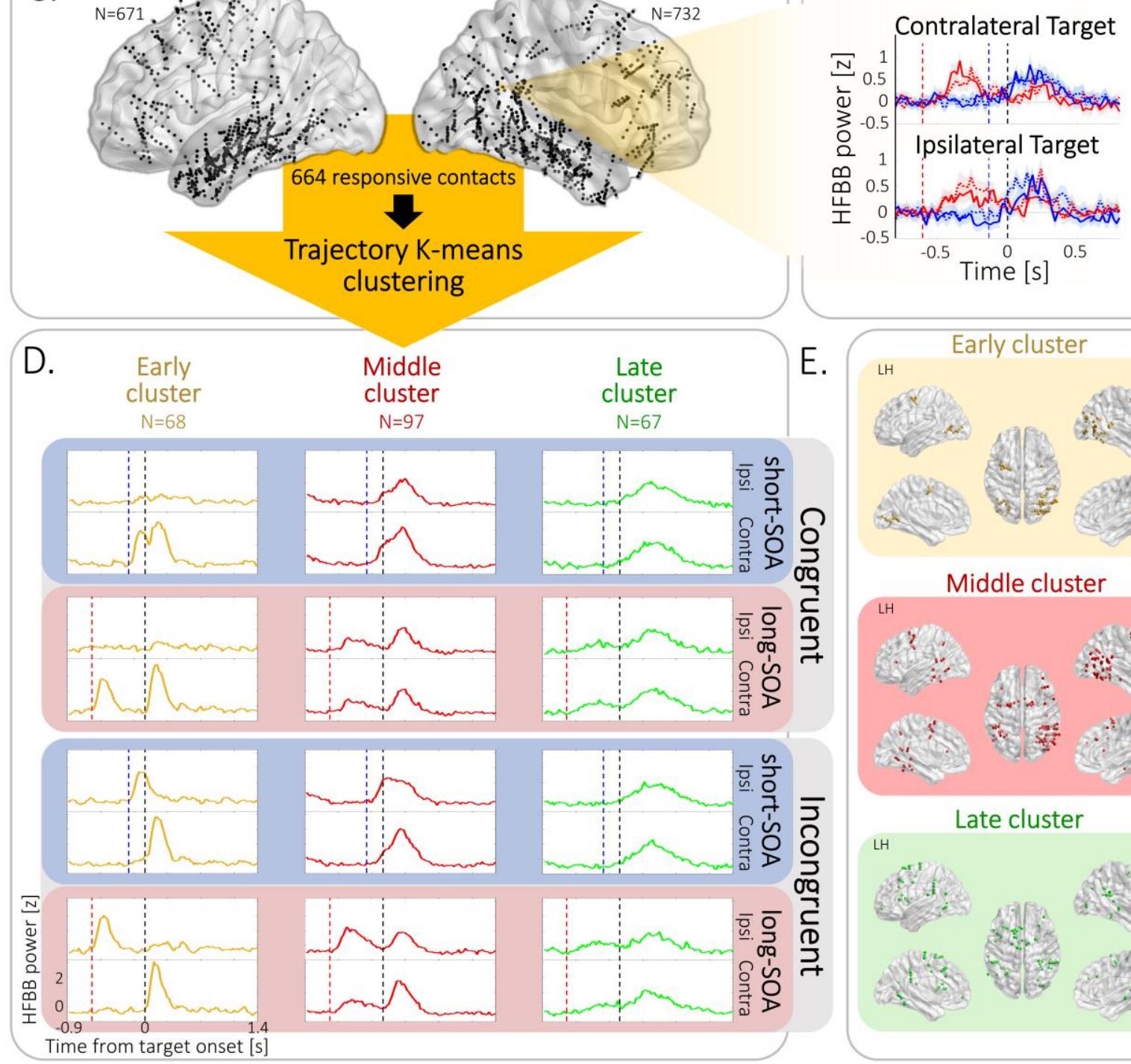

E.
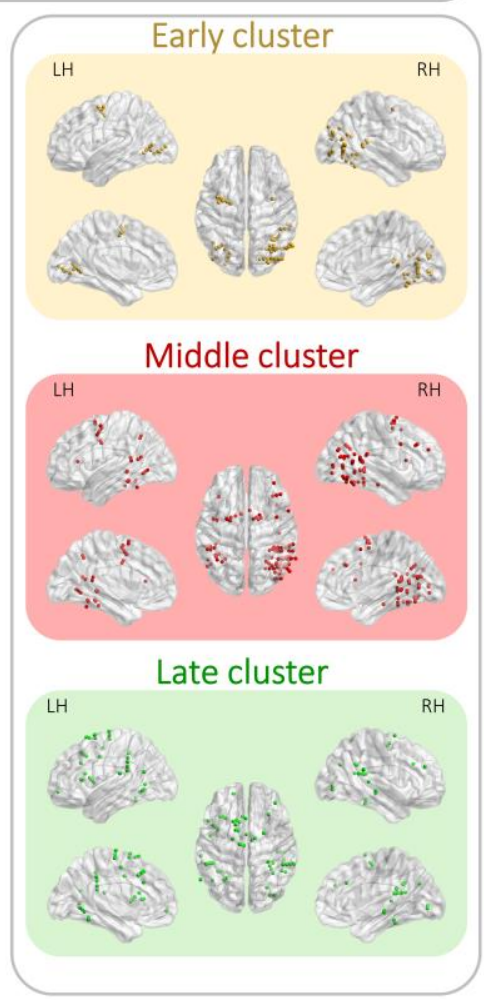

Figure 1 - Neurotypical performance of implanted patients in the Posner task, contact localization and trajectory clustering. (A) Illustration of the Posner cued detection task. After 1000ms of fixation, a cue (thickened placeholder) appeared for 100ms at either side of the screen. On short SOA trials (short-SOA), the target (' $X$ ') occurred 150ms after cue onset; on long SOA trials 
bioRxiv preprint doi: https://doi.org/10.1101/2021.01.02.425103; this version posted April 6, 2021. The copyright holder for this preprint (which was not certified by peer review) is the author/funder, who has granted bioRxiv a license to display the preprint in perpetuity. It is made available under aCC-BY-ND 4.0 International license.

(long-SOA) the target appeared 600ms after cue onset. The target appeared either on the same side of the screen as the cue (Congruent condition), or on the opposite site (Incongruent condition). Patients were required to press a central button with their right hand, as soon as the target appeared, while maintaining central fixation throughout stimuli presentation. Catch trials ( $n=24)$ had the same duration and cue presentation, but no target followed the cue. All trial types $(n=336)$ were equiprobable and randomly interleaved. Stimuli are not drawn to scale. (B) Patients' performance is neurotypical. ${ }^{*} p=0.047 ;{ }^{* *} p=0.008$; *** $p<0.001$. Error bars represent normalized SEM. (C) Left panel: Illustration of the localization of the contacts included in the analysis (black circles; $\mathrm{N}=1,403)$ in the left hemisphere ( $\mathrm{LH} ; \mathrm{N}=671)$ and in the right hemisphere $(\mathrm{RH}, \mathrm{N}=732)$, pooled across all patients. Each localization is the mean coordinates of the two contacts composing the contact's bipolar montage, depicted in normalized space (MNI152) for visualization. All included contacts were in grey matter or its immediate proximity. To reveal prototypical temporal patterns simultaneously across all conditions, the trajectories across the 8 condition dimensions of the mean high-frequency broadband (HFBB) target-locked activity of 664 significantly responsive contacts (significant time-pointby-time-point $t$-test for at least 100ms in one of the experimental conditions compared to baseline), were clustered using a novel trajectory K-means clustering approach. Right panel: Example of target-locked mean normalized HFBB responses of one contact in the right angular gyrus in Congruent (full lines) and Incongruent (dashed lines) trials, at short-SOA (blue) and long-SOA (red), with targets contralateral or ipsilateral to the contact. Dashed vertical lines represent target onset (black) and cue onset at shortSOA (blue) and long-SOA (red). Shaded areas represent SEM across trials for each sample. (D) Prototypical temporal profiles of contact clusters showing dynamic activity across experimental conditions: Trimmed-mean target-locked activity profiles of three contact clusters, across the 8 conditions (Congruent / Incongruent Trial X short-SOA / long-SOA X Ipsilateral target (Ipsi) / contralateral target (Contra)). The Early cluster (yellow) shows contralateral fast responses, with cue-target activity segregation at both SOAs; The Middle cluster (red) shows bilateral slower responses with spatial sensitivity, with cue-target activity segregation at long-SOA but response integration in short-SOA; and the Late cluster (green) shows bilateral slowest responses with stimulus type sensitivity, with cue-target activity segregation at long-SOA but response integration at short-SOA. Dashed vertical lines represent target onset (black) and cue onset at short-SOA (blue) and long-SOA (red). (E) Clusters' spatial profile. Illustration of the localization of the contacts composing each cluster: Early cluster (yellow), Middle cluster (red), Late cluster (green). For each cluster, dots represent contacts' localization in dorsal (middle), lateral (top) and medial (bottom) views of the right hemisphere ( $\mathrm{RH}$; right) and of the left hemisphere ( $\mathrm{LH}$; left). 
bioRxiv preprint doi: https://doi.org/10.1101/2021.01.02.425103; this version posted April 6, 2021. The copyright holder for this preprint (which was not certified by peer review) is the author/funder, who has granted bioRxiv a license to display the preprint in perpetuity. It is made available under aCC-BY-ND 4.0 International license.

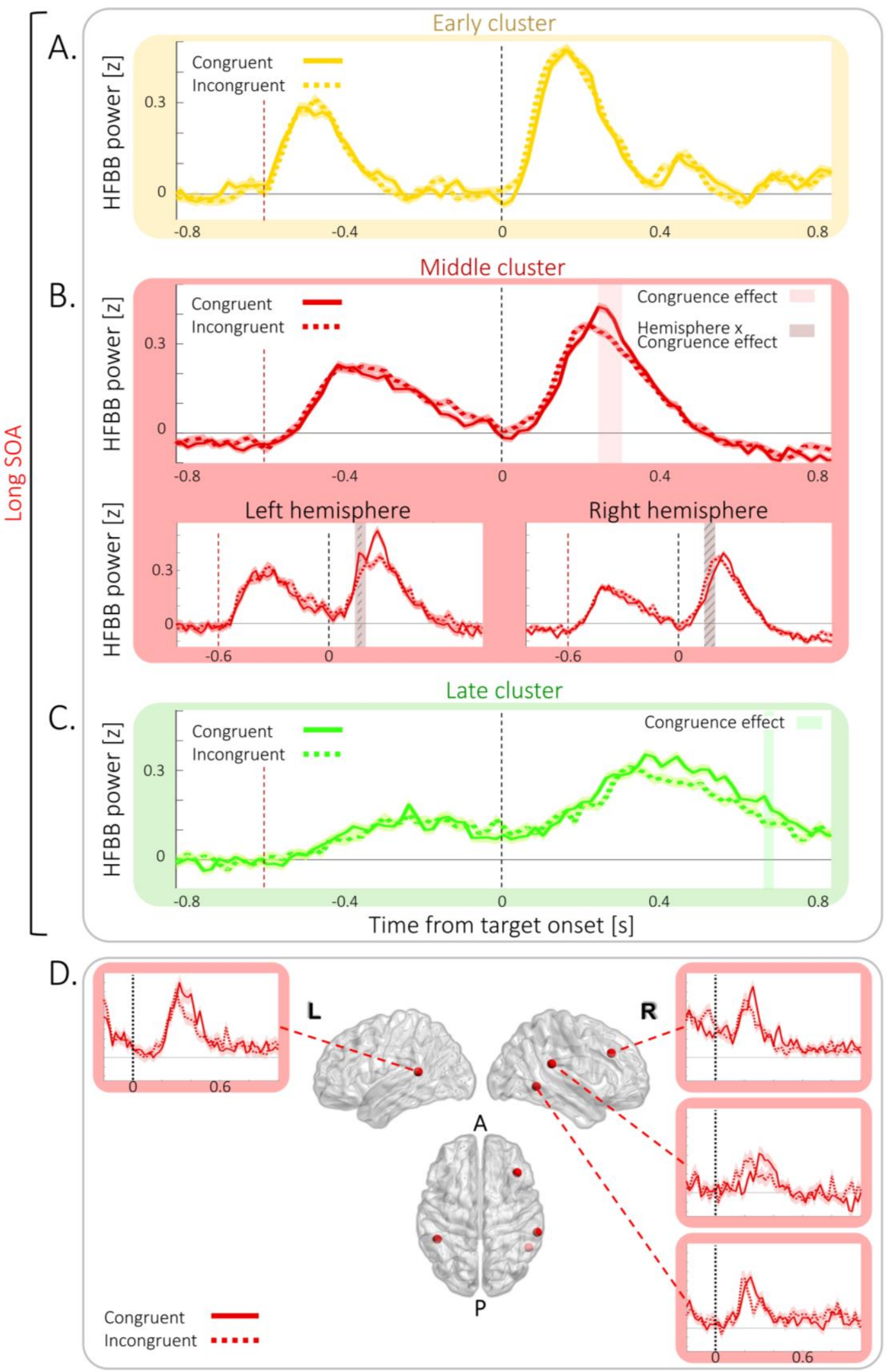

Figure 2 - IOR-related neural activity. Mean target-locked long-SOA activity in the Early (yellow), Middle (red) and Late (green) clusters, computed over trials of contacts, for Congruent trials (full lines) and Incongruent trials (dashed lines). (A) In the Early cluster, no significant Congruence effect was observed. (B) In the Middle cluster activity in Congruent and Incongruent trials 
bioRxiv preprint doi: https://doi.org/10.1101/2021.01.02.425103; this version posted April 6, 2021. The copyright holder for this preprint (which was not certified by peer review) is the author/funder, who has granted bioRxiv a license to display the preprint in perpetuity. It is made available under aCC-BY-ND 4.0 International license.

(IOR-related) differed significantly at 0.24-0.3s post target (shaded red areas; Congruence main effect: largest $p=0.002$ ), and a significant hemispheric difference between IOR-related responses was observed at 0.14-.022s post target (shaded brown area; Hemisphere $x$ Congruence interaction: largest $p=0.03)$. (C) In the Late cluster activity in Congruent and Incongruent trials differed significantly at 0.66-0.68s post target (green shaded area; Congruence main effect: largest $p=0.003$ ). A-C. Shaded areas around traces depict SEM; Dashed vertical lines represent Target onset (black) and Cue onset (red) at the long-SOA condition; Diagonally striped areas represent significant Congruence $x$ Hemisphere post hoc comparisons $(p<0.05)$. D. Representative examples of HFBB power IOR-related activity in the Congruent (full line) \& Incongruent (dashed line) long-SOA conditions of individual contacts of the Middle cluster. $p$ values are Holm corrected. 
bioRxiv preprint doi: https://doi.org/10.1101/2021.01.02.425103; this version posted April 6, 2021. The copyright holder for this preprint (which was not certified by peer review) is the author/funder, who has granted bioRxiv a license to display the preprint in perpetuity. It is made available under aCC-BY-ND 4.0 International license.

A.

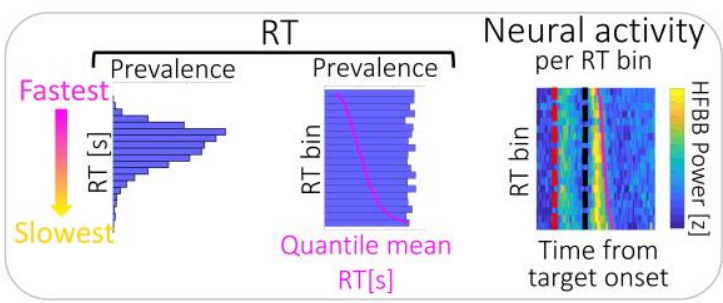

B. RT modulation of target-locked activity

Early cluster

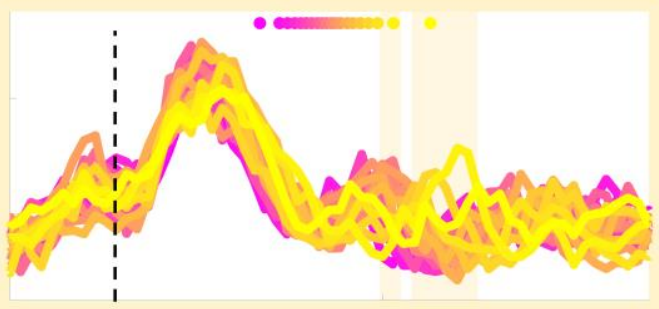

Middle cluster
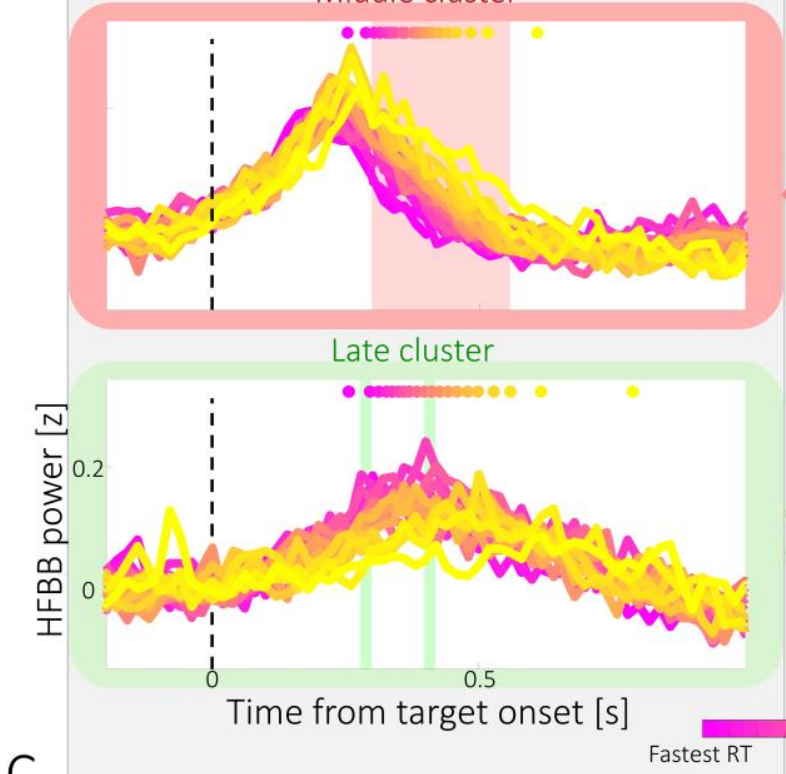

C.

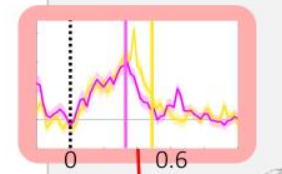

$\mathbf{L}$
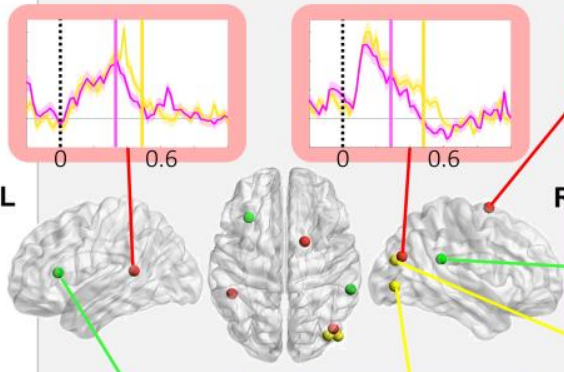

$\mathbf{R}$

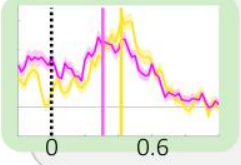

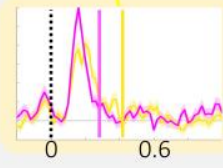

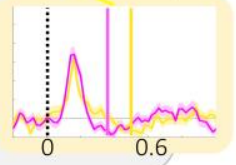

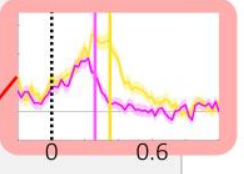

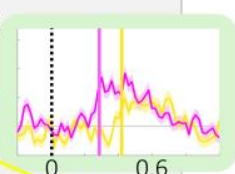

D.

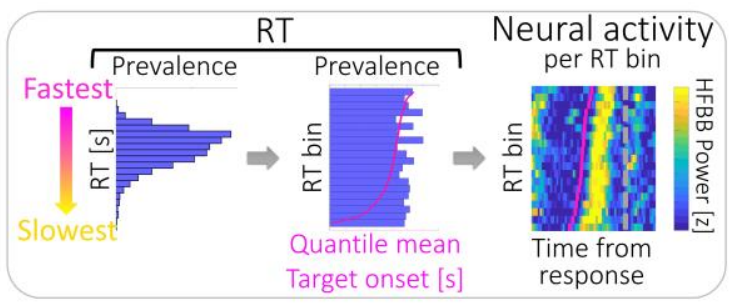

E. Visual modulation of response-locked activity RT-Early cluster

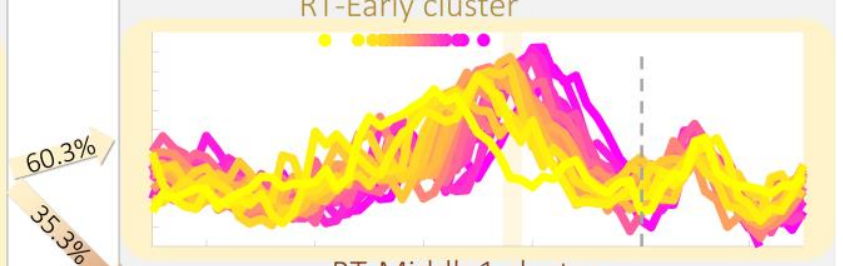

RT-Middle1 cluster

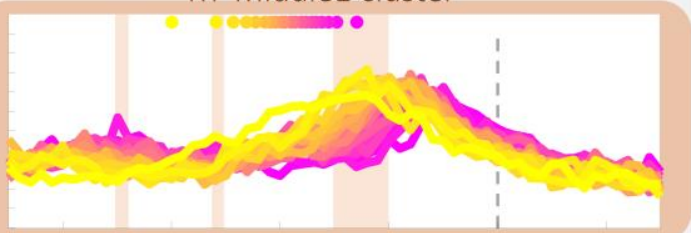

49.5\% RT-Middle2 cluster

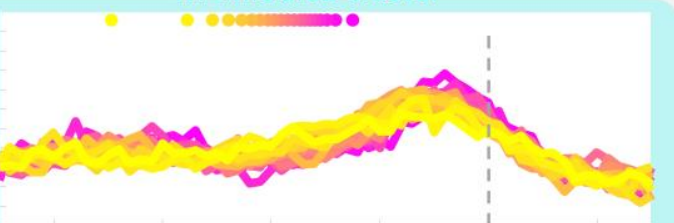

RT-Late cluster

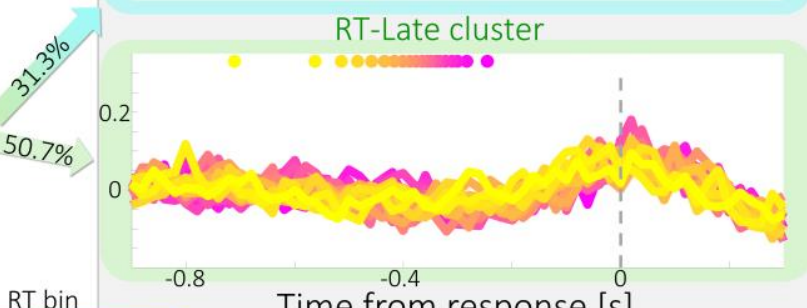

Time from response [s]

Slowest RT $F$.

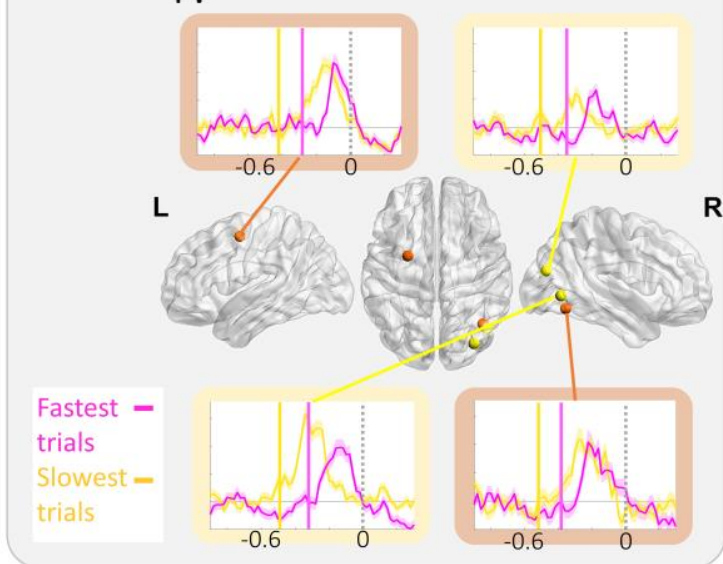


bioRxiv preprint doi: https://doi.org/10.1101/2021.01.02.425103; this version posted April 6, 2021. The copyright holder for this preprint (which was not certified by peer review) is the author/funder, who has granted bioRxiv a license to display the preprint in perpetuity. It is made available under aCC-BY-ND 4.0 International license.

Figure 3 - RT \& visual modulation of Target-locked \& Response-locked Neural activity. (A) Schematic illustration of the procedure for computing neural activity at different RT bins: Within each cluster, the trial distribution of RTs across all conditions (left) was divided into 20 quantiles (RT bins; middle). RT bins were ordered according to their mean RT (magenta line), and the quantile's mean target-locked neural activity pooled across cluster contacts, was computed (right; Vertical dashed lines denote Cue (red) \& target (black) onset; magenta line represent mean RT). (B) RT modulates target-locked neural activity (pooled across conditions; color coded from fastest (Magenta) to slowest (yellow) RT bin; Dashed vertical black line represents Target onset; Color-coded dots at the top of each panel represent mean RT for each RT bin (pink-fastest RT to yellow-slowest RT)). Top: Late RT modulation of activity in the Early cluster (yellow): Main effect of RT bin was observed at 0.5-0.54 \& 0.56-0.68s post target onset (shaded yellow area; largest $p=0.002$ ), suggesting $R T$-related late modulation after response offset \& button press time. Middle: RT modulation of neural response offset and button press time in Middle cluster (red): Main effect of RT bin was observed at 0.3-0.56s post target onset (shaded red area; largest $p=0.028$ ), suggesting $R T$ modulation of response offset. Bottom: $R T$ modulation of response in the Late cluster (green): Main effect of RT bin occurred at 0.28-0.3 and 0.4-0.42s post target onset (shaded green area; largest $p=0.007$ ), suggesting $R T$ modulation around neural response peak and button-press time. (C) Typical examples of HFBB power activity of the fastest (pink) \& slowest (yellow) third of all trials of single contacts of the three targetlocked clusters. Vertical dashed black lines represent target onset; Vertical full lines denote mean RT for fastest (magenta) \& slowest (yellow) trials. (D) Schematic illustration of the procedure for computing neural response-locked activity at different RT bins: Within each cluster, the trial distribution of RTs in each condition (left) was divided into 20 quantiles (RT bins; middle). RT bins were ordered according to their mean RT. Since RT is defined as the interval between target onset and the response, the quantile's mean RT corresponds here to target onset time (magenta line). Then, each quantile's mean response-locked neural activity pooled across all cluster contacts was computed (right; Vertical grey dashed line denote RT (black) onset; magenta line represent mean target onset time). (E) Visual modulates response-locked neural activity (pooled across conditions; color coded from fastest (Magenta) to slowest (yellow) RT bin; Dashed vertical grey line represents RT; Color-coded dots at the top of each panel represent mean target onset time for each RT bin (pink - fastest RT to yellow - slowest RT)). Top: Target onset time modulates activity in the RT-Early cluster (yellow): Main effect of RT-bin was observed at 0.12-0.10s pre-response (shaded yellow area; largest $p=0.04)$. Target onset time modulates activity in the RT-Middle1 cluster (orange): Main effect of RT bin was observed at $0.70-0.68 s, 0.52-0.50 s \& 0.30-0.20$ s pre-response (shaded orange area; largest $p=0.004$ ). No significant modulation of activity in the RT-Middle2 (turquoise) \& the RT-Late (green) clusters by target onset time. Arrows between panels (B) \& (E) denote the contingency between Target-locked \& Response-locked clusters (\% electrodes of each Target-locked cluster assigned to each Response-locked cluster; see Fig. S4). (F) Representative examples of HFBB power activity of the fastest (pink) \& slowest (yellow) third of all trials of individual contacts of the RT-Early and RT-Middle1 clusters. Vertical dashed grey lines represent RT; Vertical full lines denote mean target onset time for fastest (magenta) \& slowest (yellow) trials. $p$ values are Holm corrected. 
bioRxiv preprint doi: https://doi.org/10.1101/2021.01.02.425103; this version posted April 6, 2021. The copyright holder for this preprint (which was not certified by peer review) is the author/funder, who has granted bioRxiv a license to display the preprint in perpetuity. It is made available under aCC-BY-ND 4.0 International license.
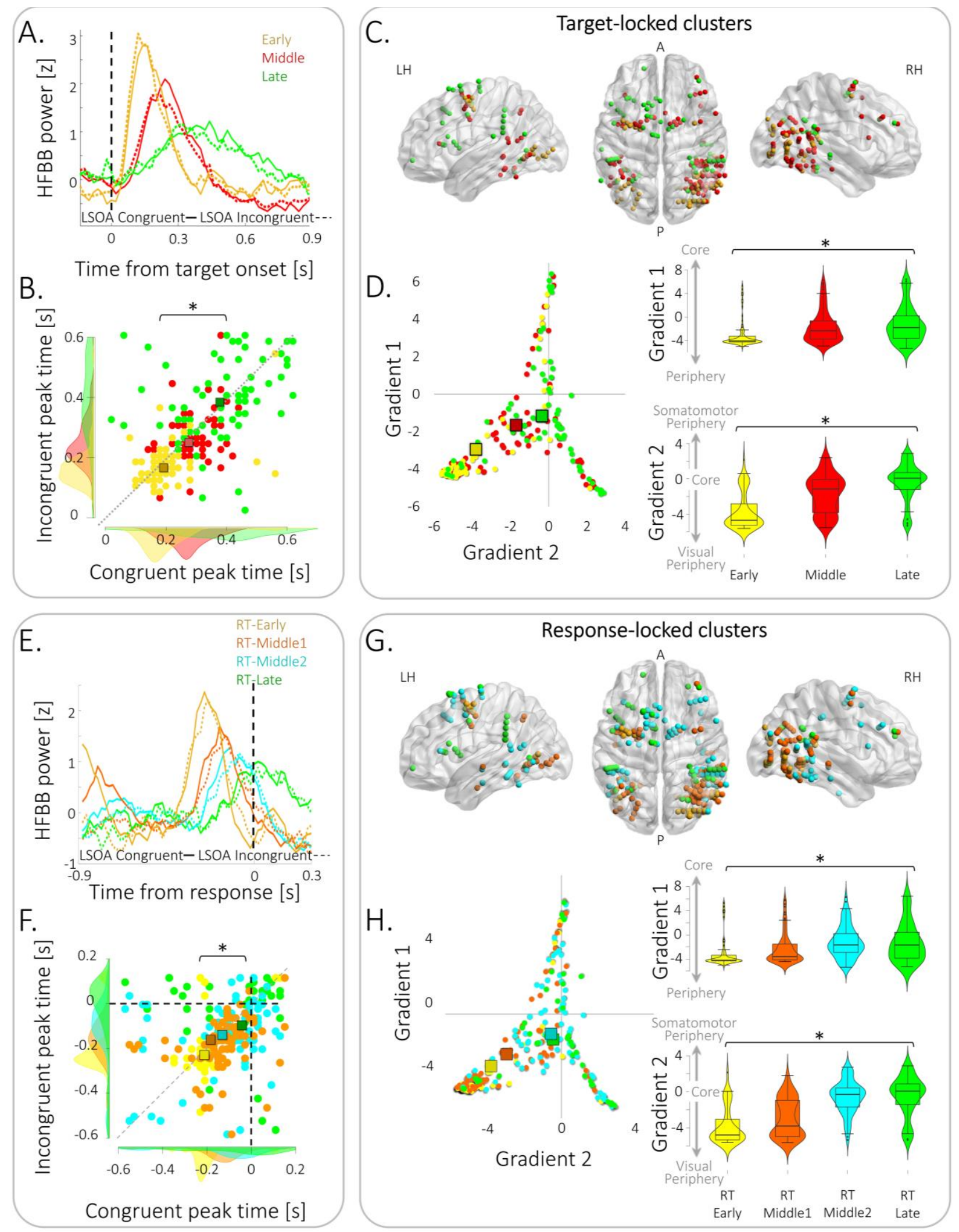

Figure 4-Clusters exhibit a spatiotemporal gradient. (A) Temporal gradient of activity in target-locked clusters: Trimmed-mean target-locked response of the Early cluster, Middle and Late clusters. Black dashed line depicts target onset. (B) Scatter plot of 
bioRxiv preprint doi: https://doi.org/10.1101/2021.01.02.425103; this version posted April 6, 2021. The copyright holder for this preprint (which was not certified by peer review) is the author/funder, who has granted bioRxiv a license to display the preprint in perpetuity. It is made available under aCC-BY-ND 4.0 International license.

peak times of mean target-locked activity of the contacts of the Early (yellow circles), the Middle (red circles) and the Late (green circles) clusters, in the Congruent ( $x$ axis) and Incongruent ( $y$-axis) conditions, showing a significant temporal gradient ( $p<0.001$, $\eta^{2}=0.378$; linear polynomial contrast: $\left.p \leq 0.001\right)$. Squares represent mean peak time; Dotted grey line denotes the equity line; Shaded areas represent peak time distributions. (C) Core-Periphery gradient: Clusters' anatomical localization follows CorePeriphery gradients (21), where the Early cluster's contacts are the most peripheral and the Late cluster's contacts are closest to core regions. (D) Left: Scatter plot of contacts localization along core-periphery gradients (Early cluster-yellow circles; Middle cluster - red circles; Late - green circles; rectangles represent clusters' mean). Right: Violin plots of contacts localization along Core-Periphery gradients for the Early (yellow), the Middle (red) and the Late (green) clusters, showing a significant coreperiphery gradient (Gradient 1: $p<0.001, \eta^{2}=0.06$; linear polynomial contrast: $p \leq 0.001$; Gradient 2: $p<0.001, \eta^{2}=0.28$; linear polynomial contrast: $p \leq 0.001)$. (E) Temporal gradient of activity in response-locked clusters: Trimmed-mean response-locked response of the RT-Early cluster, the RT-Middle1, the RT-Middle2 and the RT-Late clusters. Black dashed line depicts motor RT. (F) Scatter plot of peak times of mean response-locked activity of the contacts of the RT-Early (yellow circles), the RT-Middle1 (orange circles), the RT-Middle2 (turquoise circles) and the RT-Late (green circles) clusters, in the Congruent ( $x$ axis) and Incongruent (y-axis) long-SOA conditions, showing a significant temporal gradient $\left(p<0.001, \eta^{2}=0.086\right.$; linear polynomial contrast: $p$ 5.001). Squares represent mean peak time; Dotted grey line denotes the equity line; Shaded areas represent peak time distributions. (G) Core-Periphery gradient: Clusters' anatomical localization follows Core-Periphery gradients (21), where the RT-Early cluster's contacts are the most peripheral and the RT-Late cluster's contacts are closest to core regions. (H) Left: Scatter plot of contacts localization along core-periphery gradients (RT-Early cluster-yellow circles; RT-Middle1 cluster-orange circles; RT-Middle2 cluster - turquoise circles; RT-Late cluster-green circles; rectangles represent clusters' mean). Right: Violin plots of contacts localization along Core-Periphery gradients for the RT-Early (yellow), the RT-Middle1 (orange), the RT-Middle2 (turquoise) and the RT-Late (green) clusters, showing a significant core-periphery gradient (Gradient 1: $p=0.001, \eta^{2}=0.06$; linear polynomial contrast: $p \leq 0.001$; Gradient 2: $p<0.001, \eta^{2}=0.32$; linear polynomial contrast: $p \leq 0.001$ ). 
bioRxiv preprint doi: https://doi.org/10.1101/2021.01.02.425103; this version posted April 6, 2021. The copyright holder for this preprint (which was not certified by peer review) is the author/funder, who has granted bioRxiv a license to display the preprint in perpetuity. It is made available under aCC-BY-ND 4.0 International license.

\begin{tabular}{|c|c|c|c|c|c|c|}
\hline Patient \# & Age & Gender & Handedness & $\begin{array}{l}\text { Number of } \\
\text { electrodes } \\
\text { (total 243) }\end{array}$ & $\begin{array}{l}\text { Total number } \\
\text { of contacts } \\
\text { (total } 1,884 \text { ) }\end{array}$ & $\begin{array}{l}\text { Implanted } \\
\text { hemisphere }\end{array}$ \\
\hline 1 & 49 & M & $R$ & 10 & 104 & $\mathrm{RH}$ \\
\hline 2 & 44 & $\mathrm{~F}$ & $R$ & 12 & 96 & $\mathrm{LH}+\mathrm{RH}$ \\
\hline 3 & 31 & M & $\mathrm{R}$ & 12 & 82 & $\mathrm{RH}$ \\
\hline 4 & 31 & $\mathrm{~F}$ & R & 10 & 82 & $\mathrm{LH}$ \\
\hline 5 & 26 & M & R & 9 & 58 & $\mathrm{RH}$ \\
\hline 6 & 47 & M & $\mathrm{R}$ & 11 & 90 & $\mathrm{LH}$ \\
\hline 7 & 31 & $\mathrm{~F}$ & $R$ & 9 & 54 & $\mathrm{LH}$ \\
\hline 8 & 30 & M & $R$ & 9 & 63 & $\mathrm{LH}$ \\
\hline 9 & 26 & M & $L+R$ & 10 & 44 & $\mathrm{LH}+\mathrm{RH}$ \\
\hline 10 & 24 & M & $\mathrm{R}$ & 9 & 48 & $\mathrm{LH}$ \\
\hline 11 & 26 & $\mathrm{~F}$ & $R$ & 10 & 88 & $\mathrm{LH}$ \\
\hline 12 & 22 & $\mathrm{~F}$ & $R$ & 10 & 58 & $\mathrm{RH}$ \\
\hline 13 & 34 & $\mathrm{~F}$ & $R$ & 8 & 76 & $\mathrm{LH}$ \\
\hline 14 & 40 & $\mathrm{~F}$ & $R$ & 7 & 62 & $\mathrm{LH}$ \\
\hline 15 & 34 & M & $R$ & 10 & 70 & $\mathrm{LH}+\mathrm{RH}$ \\
\hline 16 & 45 & $\mathrm{~F}$ & R & 9 & 78 & $\mathrm{LH}+\mathrm{RH}$ \\
\hline 17 & 24 & $\mathrm{~F}$ & R & 8 & 61 & $\mathrm{RH}$ \\
\hline 18 & 19 & $M$ & $\mathrm{R}$ & 7 & 65 & $\mathrm{RH}$ \\
\hline 19 & 34 & $M$ & $R$ & 7 & 31 & $\mathrm{RH}$ \\
\hline 20 & 47 & M & $R$ & 8 & 53 & $\mathrm{LH}$ \\
\hline 21 & 31 & $\mathrm{~F}$ & $\mathrm{~L}$ & 8 & 56 & $\mathrm{LH}$ \\
\hline 22 & 31 & M & L & 5 & 48 & $\mathrm{LH}$ \\
\hline 23 & 26 & $\mathrm{~F}$ & R & 8 & 63 & $\mathrm{RH}$ \\
\hline 24 & 26 & $\mathrm{~F}$ & $\mathrm{R}$ & 9 & 77 & $\mathrm{RH}$ \\
\hline 25 & 31 & $\mathrm{~F}$ & $R$ & 9 & 67 & $\mathrm{LH}+\mathrm{RH}$ \\
\hline 26 & 21 & $\mathrm{~F}$ & $R$ & 9 & 54 & $L H+R H$ \\
\hline 27 & 30 & $\mathrm{~F}$ & $\mathrm{R}$ & 12 & 93 & $\mathrm{RH}$ \\
\hline 28 & 28 & $M$ & $\mathrm{R}$ & 11 & 62 & $\mathrm{LH}$ \\
\hline Mean & $31.7 \pm 8.1$ & $54 \% \mathrm{~F}$ & $89 \% R$ & 9.1 & 67.3 & $57 \%$ RH \\
\hline
\end{tabular}


bioRxiv preprint doi: https://doi.org/10.1101/2021.01.02.425103; this version posted April 6, 2021. The copyright holder for this preprint (which was not certified by peer review) is the author/funder, who has granted bioRxiv a license to display the preprint in perpetuity. It is made available under aCC-BY-ND 4.0 International license.

\begin{tabular}{|c|c|c|c|c|}
\hline Region name & $\begin{array}{c}\text { Responsive } \\
\text { Electrodes } \\
\text { N }\end{array}$ & $\begin{array}{l}\text { Early cluster } \\
\qquad \mathrm{N}\end{array}$ & $\begin{array}{c}\text { Middle cluster } \\
\text { N }\end{array}$ & $\begin{array}{l}\text { Late cluster } \\
\text { N }\end{array}$ \\
\hline Banks superior temporal sulcus & 9 & 1 & 4 & 1 \\
\hline Caudal anterior-cingulate cortex & 3 & 0 & 0 & 0 \\
\hline Caudal middle frontal gyrus & 12 & 2 & 2 & 1 \\
\hline Entorhinal cortex & 6 & 0 & 0 & 0 \\
\hline Fusiform gyrus Posterior & 33 & 7 & 8 & 3 \\
\hline Fusiform gyrus Med & 14 & 2 & 2 & 0 \\
\hline Fusiform gyrus Anterior & 10 & 0 & 0 & 0 \\
\hline Inferior parietal cortex & 51 & 19 & 14 & 5 \\
\hline Inferior temporal gyrus Posterior & 28 & 1 & 8 & 1 \\
\hline Inferior temporal gyrus Middle & 14 & 0 & 3 & 0 \\
\hline Inferior temporal gyrus Antrior & 13 & 0 & 0 & 0 \\
\hline Lateral occipital cortex & 20 & 6 & 5 & 2 \\
\hline Lingual gyrus & 17 & 1 & 0 & 3 \\
\hline Medial orbital frontal cortex & 4 & 0 & 0 & 0 \\
\hline Middle temporal gyrus Posterior & 37 & 10 & 12 & 1 \\
\hline Middle temporal gyrus Middle & 19 & 0 & 2 & 0 \\
\hline Middle temporal gyrus Anterior & 35 & 0 & 0 & 0 \\
\hline Parahippocampal gyrus & 8 & 0 & 0 & 0 \\
\hline Paracentral lobule & 1 & 0 & 0 & 0 \\
\hline Pars opercularis & 8 & 0 & 0 & 1 \\
\hline Pars orbitalis & 36 & 0 & 0 & 0 \\
\hline Pars triangularis & 9 & 0 & 0 & 4 \\
\hline Pericalcarine cortex & 1 & 0 & 0 & 0 \\
\hline Postcentral gyrus dorsal & 1 & 0 & 0 & 0 \\
\hline Postcentral gyrus ventral & 1 & 0 & 0 & 0 \\
\hline Posterior-cingulate cortex & 3 & 0 & 1 & 1 \\
\hline Precentral gyrus dorsal & 16 & 6 & 3 & 4 \\
\hline Precentral gyrus ventral & 5 & 0 & 3 & 1 \\
\hline Precuneus cortex & 1 & 0 & 0 & 0 \\
\hline Rostral middle frontal gyrus & 16 & 0 & 4 & 2 \\
\hline Superior frontal gyrus & 46 & 0 & 8 & 16 \\
\hline Superior parietal cortex & 10 & 1 & 3 & 1 \\
\hline Superior temporal gyrus Posterior & 19 & 2 & 1 & 3 \\
\hline Superior temporal gyrus Middle & 17 & 0 & 0 & 0 \\
\hline Superior temporal gyrus Anterior & 13 & 0 & 0 & 3 \\
\hline Supramarginal gyrus & 22 & 0 & 3 & 9 \\
\hline Temporal pole & 14 & 0 & 0 & 0 \\
\hline White matter & 49 & 10 & 10 & 5 \\
\hline hippocampus & 18 & 0 & 1 & 0 \\
\hline amygdala & 5 & 0 & 0 & 0 \\
\hline
\end{tabular}

Table 2 - Responsive electrodes localization according to the Desikan-Killiany-Tourville atlas (42) 
A.

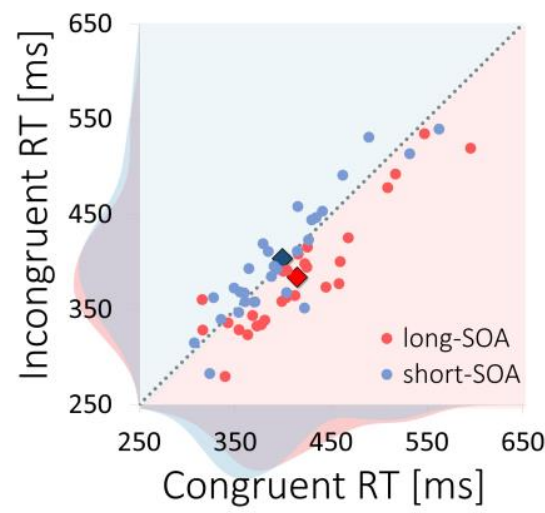

B.

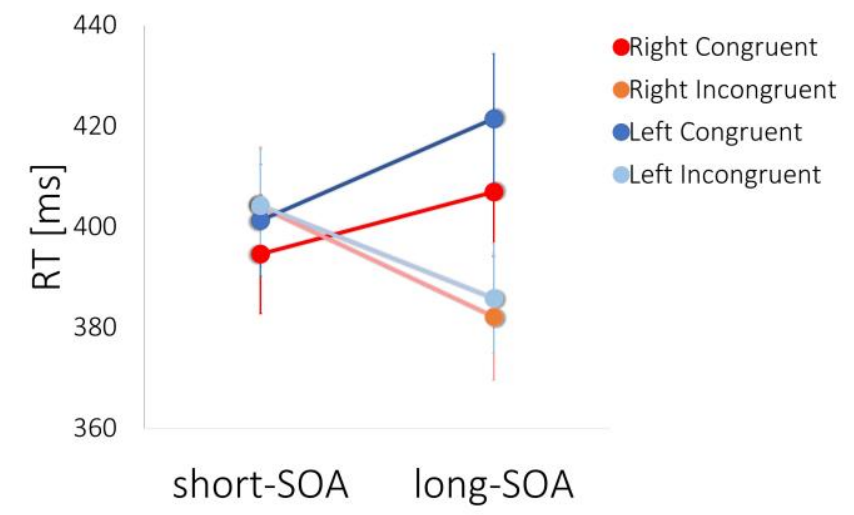

Figure S1- Behavioral effects. (A) Individual RT effects. A scatter plot of patients' RT, showing each patient's Congruent trials' RT (X axis) and Incongruent trials' RT (y axis), in the Long SOA condition (long-SOA; red dots) and in the Short SOA condition (short-SOA; blue dots). Squares represent group mean RT. Dotted line denotes the equity line, samples below it demonstrate IOR (shaded red), and samples above it demonstrate RT facilitation (shaded blue). RT distributions for long-SOA (shaded red) and short-SOA (shaded blue) conditions, for congruent trials (x-axis) and Incongruent trials (y-axis). (B) RT effects for right-\& left-sided targets. Left target Congruent RTs were slower than right target Congruent RTs, across both SOAs (repeated-measures 3-way ANOVA: Target-side X Congruence interaction $\left.-F_{(1,27)}=8.28, p=0.008, \eta^{2}=0.007\right)$, reflecting the Poffenberger effect, i.e. faster $R$ Ts for right cue \& target than for left cue \& target, when responding with the right hand. In Incongruent trials in which cue \& target appear at opposite sides of the screen, this effect might have averaged out. No other Target-side effects reached significance, and IOR and RT-facilitation effects did not significantly differ between left sided and right sided targets. 
bioRxiv preprint doi: https://doi.org/10.1101/2021.01.02.425103; this version posted April 6, 2021. The copyright holder for this preprint (which was not certified by peer review) is the author/funder, who has granted bioRxiv a license to display the preprint in perpetuity. It is made available under aCC-BY-ND 4.0 International license.

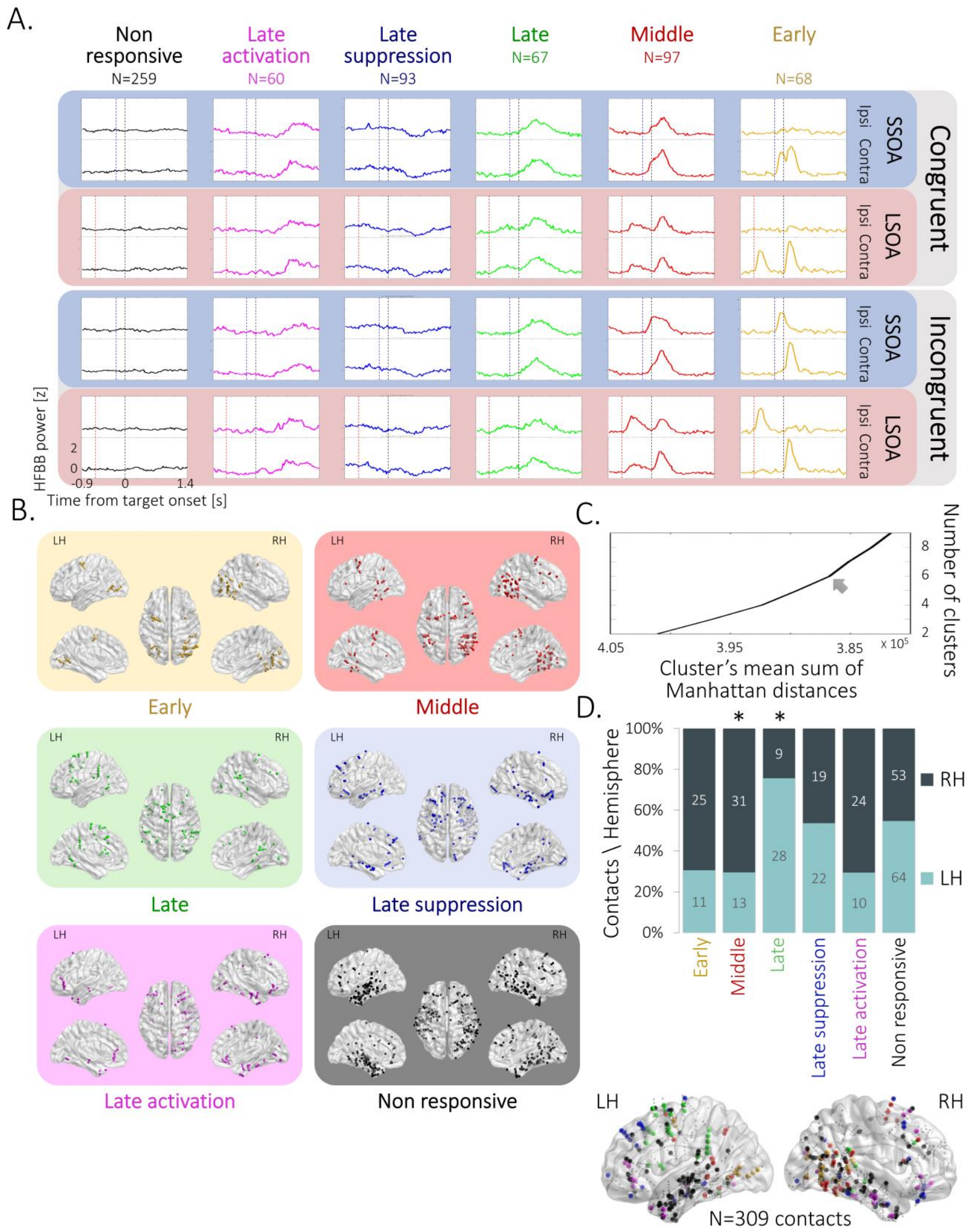

Figure S2 - Clusters' spatiotemporal profile. (A) Prototypical activity profiles of contact clusters: Trimmed-mean target-locked activity profiles of the six contact clusters: Early cluster (yellow); Middle cluster (red); Late cluster (green); Late suppression cluster (blue); Late activation cluster (magenta); Non responsive cluster (black), across the 8 conditions (Congruent / Incongruent X short- 
bioRxiv preprint doi: https://doi.org/10.1101/2021.01.02.425103; this version posted April 6, 2021. The copyright holder for this preprint (which was not certified by peer review) is the author/funder, who has granted bioRxiv a license to display the preprint in perpetuity. It is made available under aCC-BY-ND 4.0 International license.

SOA / long-SOA X Ipsilateral target (Ipsi) / contralateral target (Contra)). Dashed vertical lines represent Target onset (black) and Cue onset at short-SOA (blue) and long-SOA (red) conditions. (B) Clusters' spatial profile. Illustration of the localization of the contacts composing each cluster: Early cluster (yellow); Middle cluster (red); Late cluster (green); Late suppression cluster (blue); Late activation cluster (magenta); Non responsive cluster (black). For each cluster, dots represent contacts' localization, computed as the mean coordinates of the two contacts composing each contact's bipolar montage, depicted in normalized space (MNI152) in dorsal (middle), lateral (top) and medial (bottom) views in the right hemisphere ( $\mathrm{RH}$; right) and the left hemisphere (LH; left). (C) Elbow method. Mean sum of Manhattan distances between each contact trajectory and its assign cluster trajectory for 2-9 clusters' solution. Maximal elbow (grey arrow) is observed at the 6-cluster solution. Clusters' hemispheric lateralization. (D) Clusters' spatial distribution in symmetrically covered regions significantly differs between right and left hemispheres (dark grey \& light grey respectively; $X_{(5)}{ }_{(5)} 29.09, p<0.001$ ), resulting from a significant right lateralization of Middle cluster (red) and a significant left lateralization of Late cluster (green; post hoc binomial tests, $p=0.01$ and $p=0.003$ ). Symmetrically covered regions were defined by calculating the overlap between the volumes of $3 \mathrm{~mm}$ radius spheres around each contact for each hemisphere (see methods). Proportion of colors in each bar represent the percentage of contacts per hemisphere in each cluster; numbers are raw contact number per hemisphere in each cluster. 
bioRxiv preprint doi: https://doi.org/10.1101/2021.01.02.425103; this version posted April 6, 2021. The copyright holder for this preprint (which was not certified by peer review) is the author/funder, who has granted bioRxiv a license to display the preprint in perpetuity. It is made available under aCC-BY-ND 4.0 International license.

A.

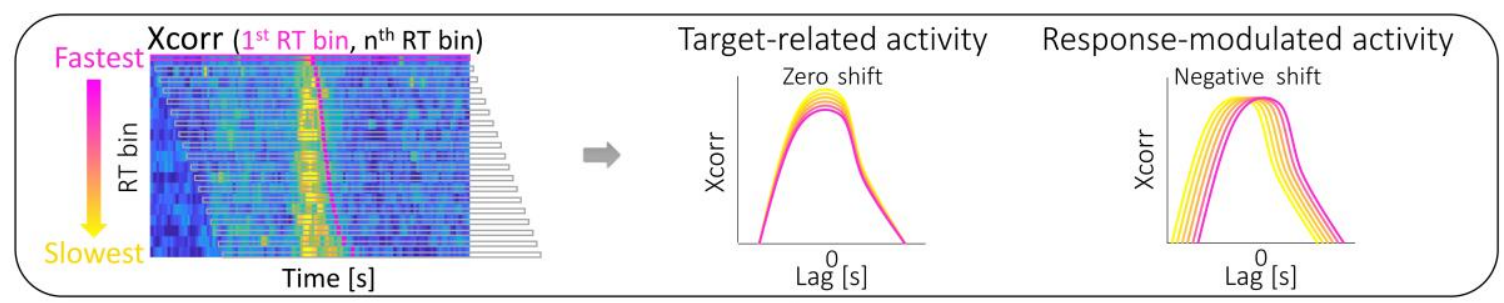

B.

Early cluster

C.

Middle cluster
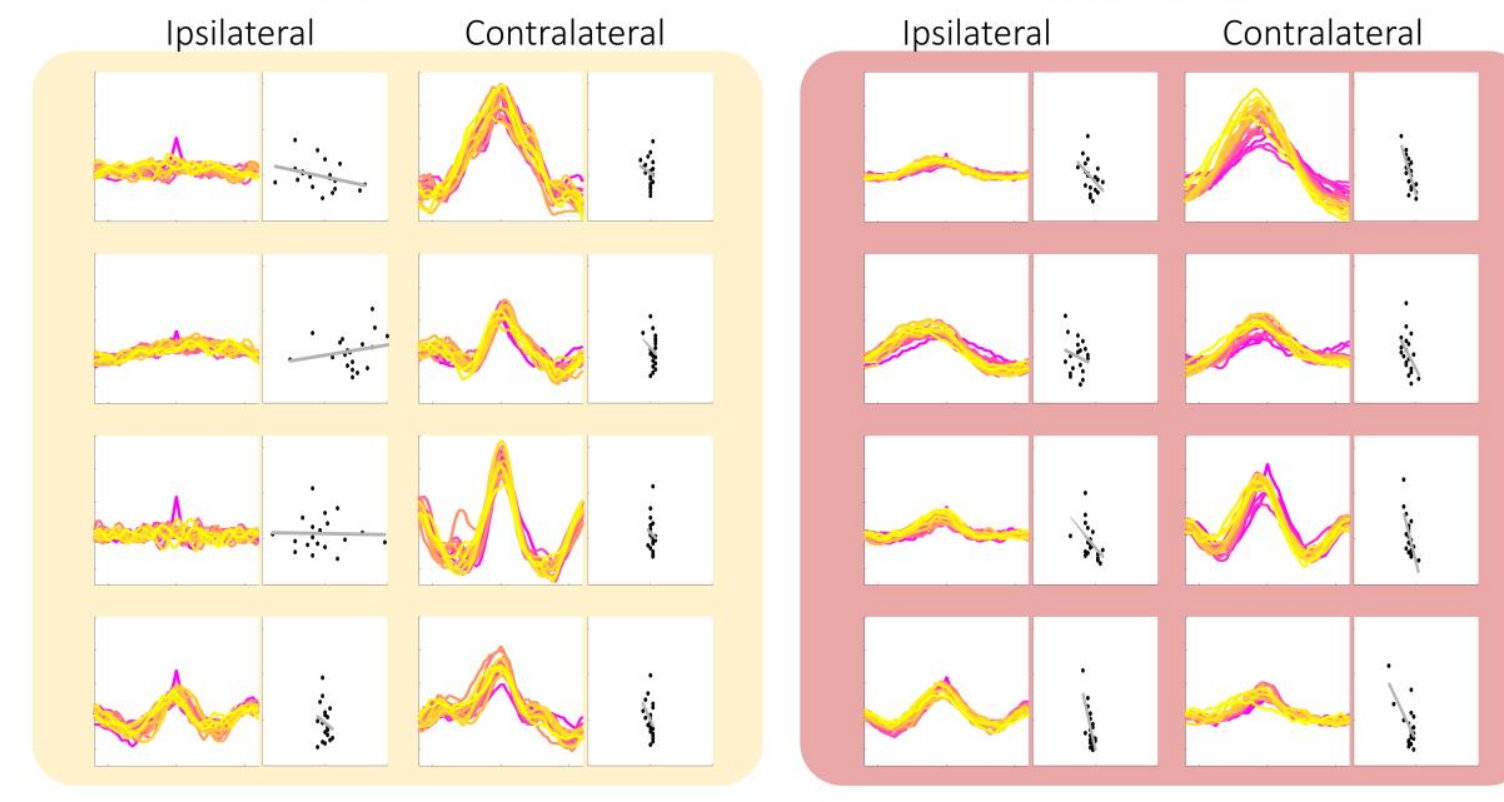

D.

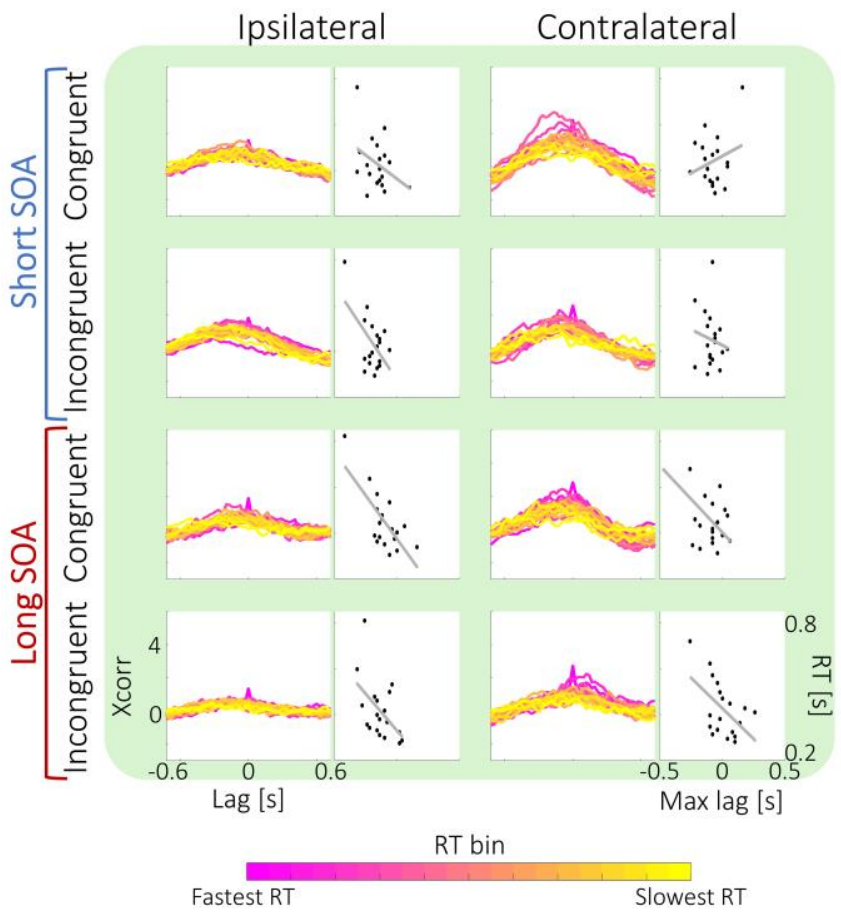

E.

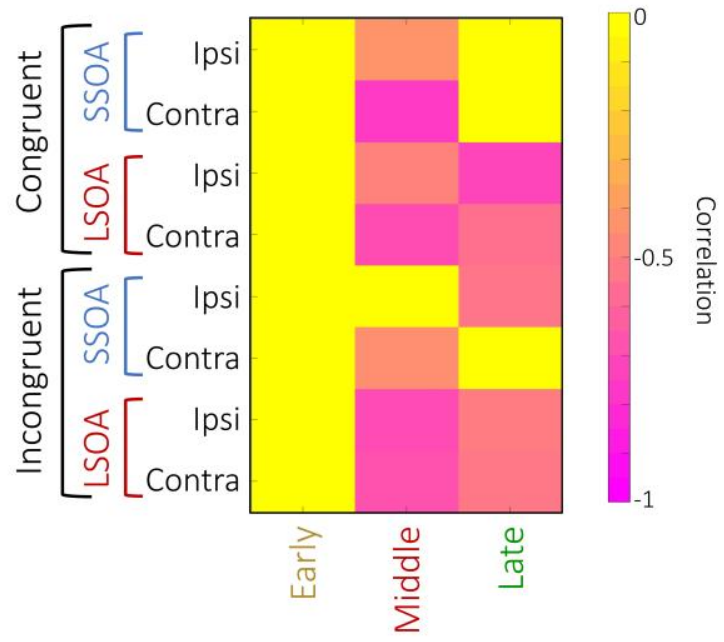


bioRxiv preprint doi: https://doi.org/10.1101/2021.01.02.425103; this version posted April 6, 2021. The copyright holder for this preprint (which was not certified by peer review) is the author/funder, who has granted bioRxiv a license to display the preprint in perpetuity. It is made available under aCC-BY-ND 4.0 International license.

Figure S3 - Cluster neural target-locked activity timing is correlated with behavior. (A) Schematic illustration of the procedure for computing the cross-correlation (Xcorr) between neural activity across RT bins: Cross-correlation between target-locked activity at the fastest RT bin and all subsequent bins was computed (left). If cluster activity is target-associated, maximal cross-correlation will be centered around target onset, resulting in a zero shift across all RT bins (middle). If cluster activity is response-associated, maximal cross-correlation will follow the RT, resulting in a negative shift of cross-correlation lag (right). (B)-(D). Crosscorrelogram of neural activity at different RT bins (pink-fastest RT; yellow - slowest RT) as a function of cross-correlation lag (left columns) and Pearson correlation (grey line) between maximal cross-correlation lags (Max lag) and bin's mean RTs (right columns), across the 8 conditions (Congruent / Incongruent X short-SOA / long-SOA X Ipsilateral target / contralateral target) in the Early (yellow), Middle (red) and Late (green) clusters. (B) Early cluster activity is target-associated: Cross-correlation plots are centered around zero, especially for contralateral targets. (C) Activity in the Middle cluster is response-associated: Crosscorrelation plots show a negative shifted lag that is generally correlated with RT. (D) Late cluster activity is response-associated: Cross-correlation plots show a negative shifted lag, correlated with RT under certain conditions. (E) Significant negative correlation between cross-correlation maximal lag and bin mean RT in the Middle \& Late clusters: significant $(p<0.05)$ negative correlations were found only in these two clusters. 
bioRxiv preprint doi: https://doi.org/10.1101/2021.01.02.425103; this version posted April 6, 2021. The copyright holder for this preprint (which

was not certified by peer review) is the author/funder, who has granted bioRxiv a license to display the preprint in perpetuity. It is made available under aCC-BY-ND 4.0 International license.

A.

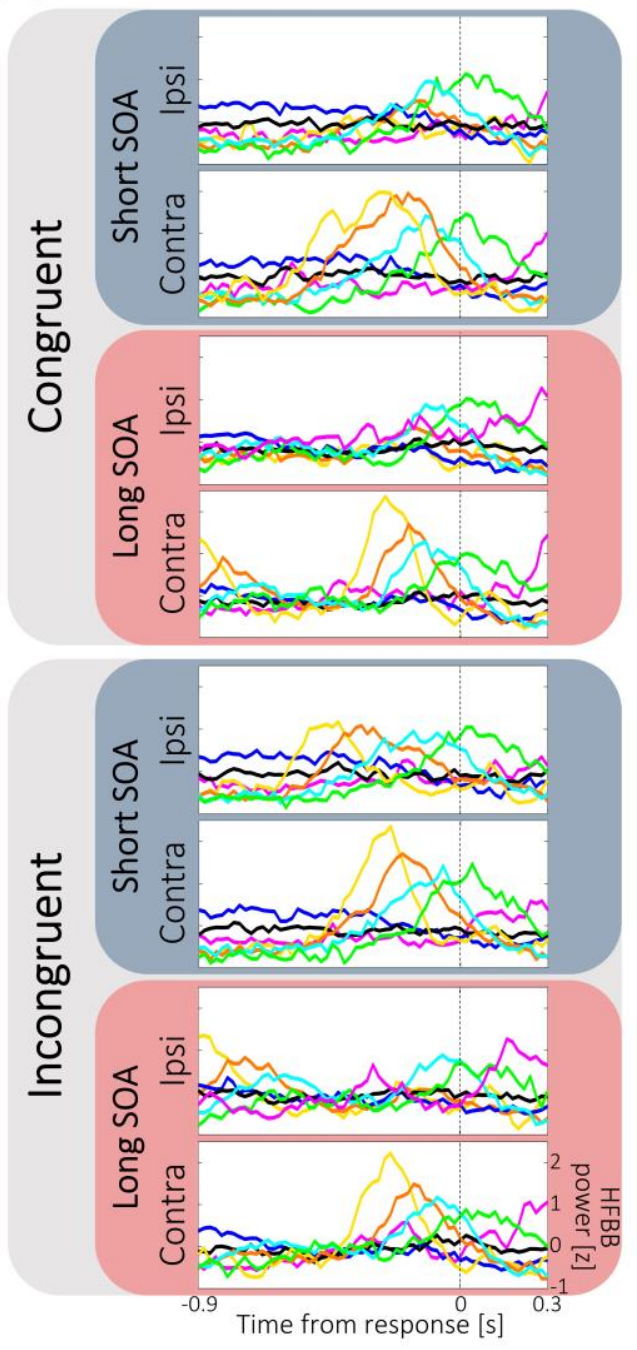

B.

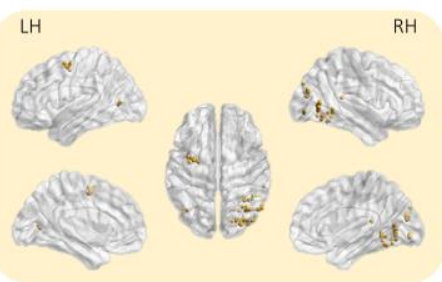

RT-Early $\mathrm{N}=46$

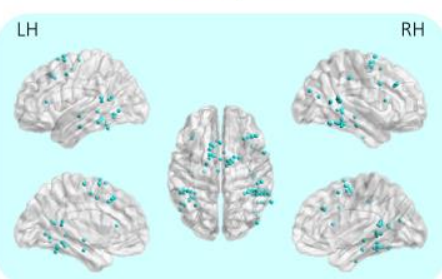

RT-Middle2 $\mathrm{N}=79$

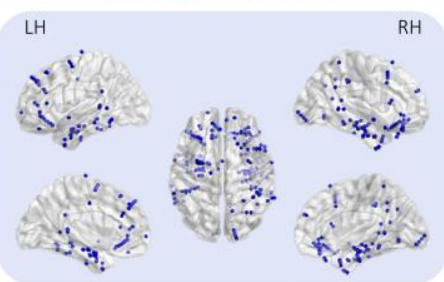

RT-Late suppression $\mathrm{N}=145$

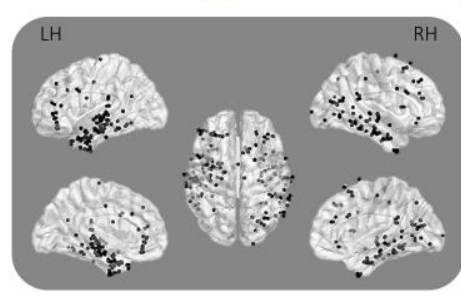

RT-Non responsive $\mathrm{N}=199$

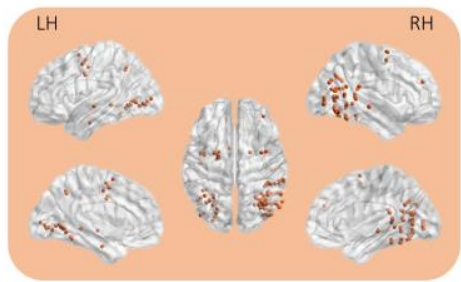

RT-Middle1 N=85

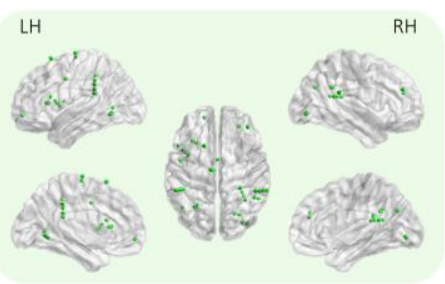

RT-Late $\mathrm{N}=39$

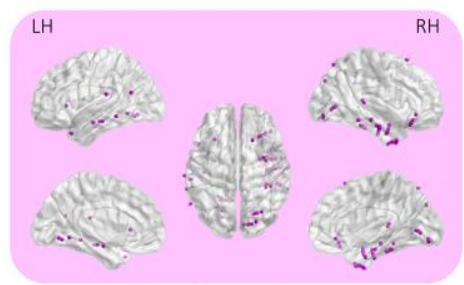

C. RT-Late Activation $\mathrm{N}=51$

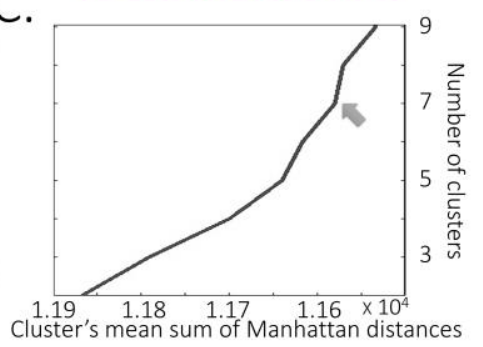

D. Response-locked clusters

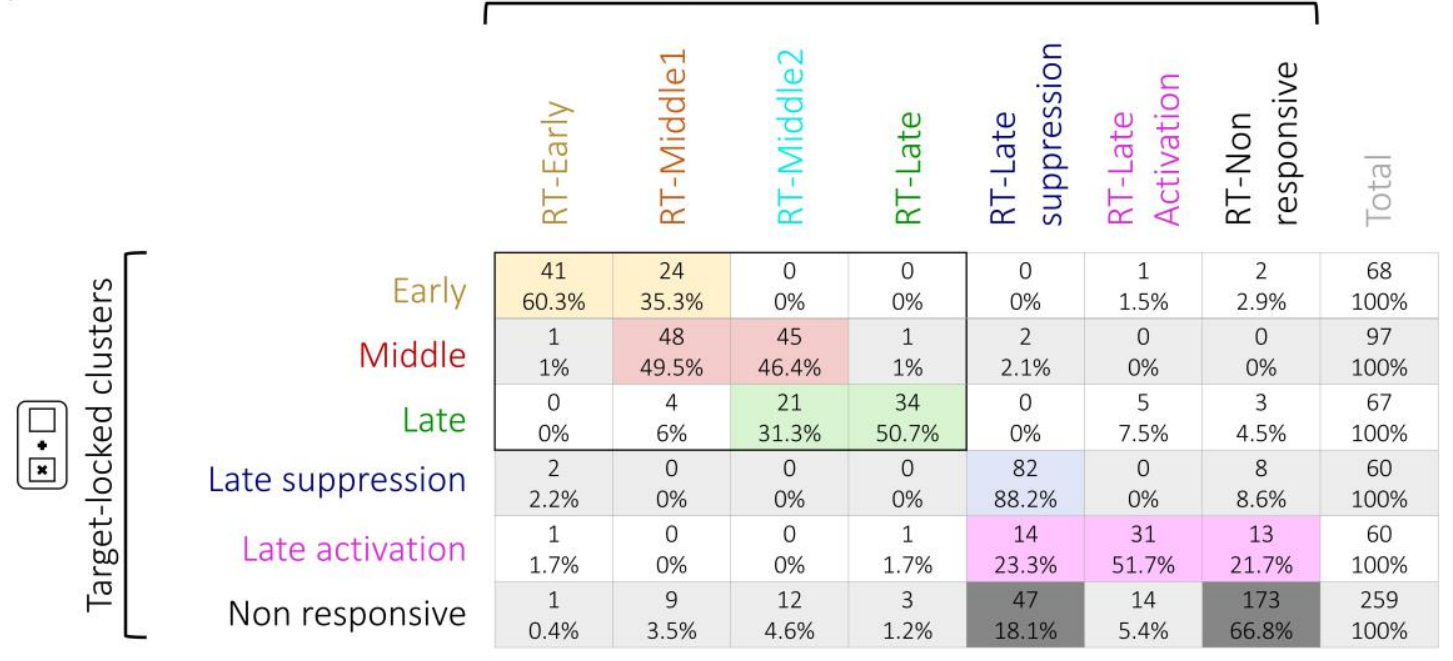


bioRxiv preprint doi: https://doi.org/10.1101/2021.01.02.425103; this version posted April 6, 2021. The copyright holder for this preprint (which was not certified by peer review) is the author/funder, who has granted bioRxiv a license to display the preprint in perpetuity. It is made available under aCC-BY-ND 4.0 International license.

Figure S4 - Response-locked clusters' spatiotemporal profile. (A) Trimmed-mean response-locked activity profiles of the seven contact clusters across the 8 conditions (Congruent / Incongruent X short-SOA / long-SOA X Ipsilateral target / contralateral target): RT-Early cluster (yellow); RT-Middle1 cluster (orange); RT-Middle2 cluster (turquoise); RT-Late cluster (green); RT-Late suppression cluster (blue); RT-Late activation cluster (magenta); RT-Non responsive cluster (black). Dashed vertical line represents motor response time. (B) Response-locked clusters' spatial location. Illustration of the localization of the contacts composing each cluster (colors as in A). For each cluster, dots represent contacts' localization, computed as the mean coordinates of the two contacts composing each contact's bipolar montage, depicted in normalized space (MNI152) in dorsal (middle), lateral (top) and medial (bottom) views in the right hemisphere (RH) and the left hemisphere (LH). (C) Elbow method. Mean sum of Manhattan distances between each contact trajectory and its assigned cluster trajectory for 2-9 clusters' solution. Maximal elbow (grey arrow) is observed at 7-cluster solution. (D) Contingency table showing the mapping between target-locked and response-locked clusters. The distribution of target-locked clusters' contacts (rows; number of contacts \& \% within row) across the different response-locked clusters (columns) was significantly different than chance $\left(X^{2}{ }_{(30)}=1442 ; p<0.001\right.$; Contingency coefficient $=0.83$ ). 
bioRxiv preprint doi: https://doi.org/10.1101/2021.01.02.425103; this version posted April 6, 2021. The copyright holder for this preprint (which was not certified by peer review) is the author/funder, who has granted bioRxiv a license to display the preprint in perpetuity. It is made available under aCC-BY-ND 4.0 International license.

A.
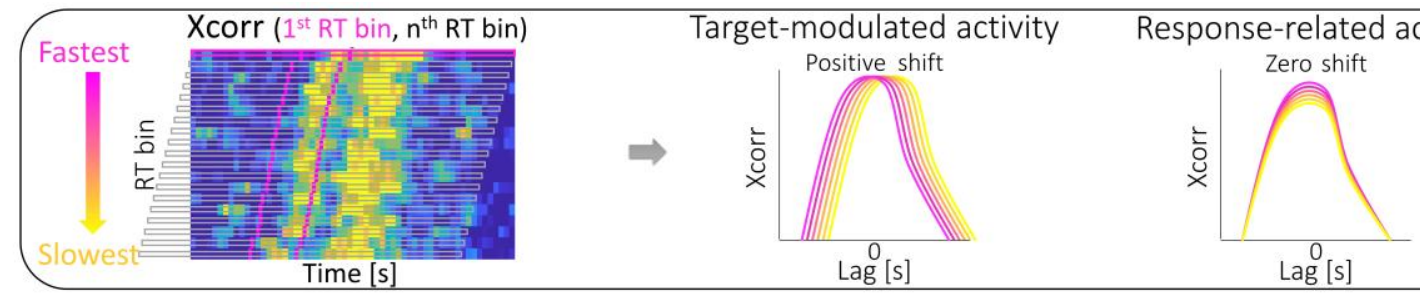

B.

RT-Early cluster

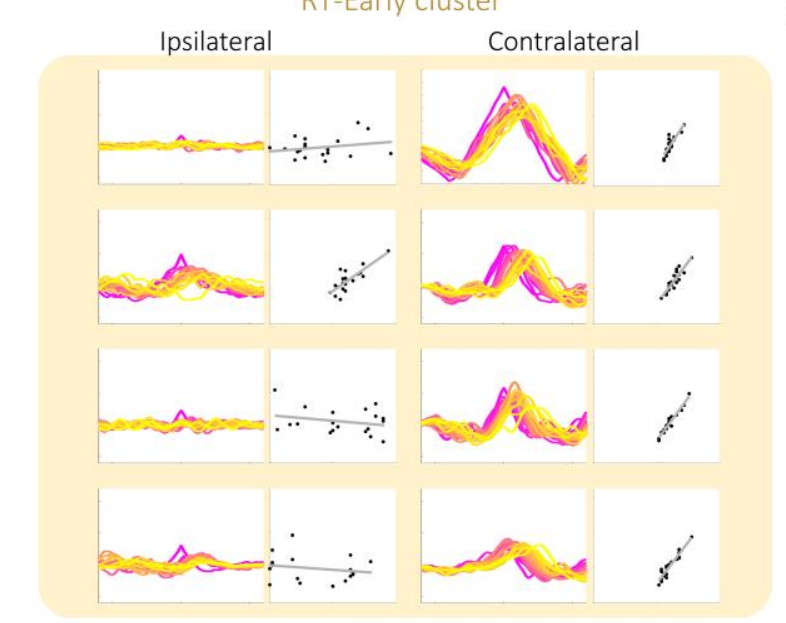

C.

RT-Middle1 cluster

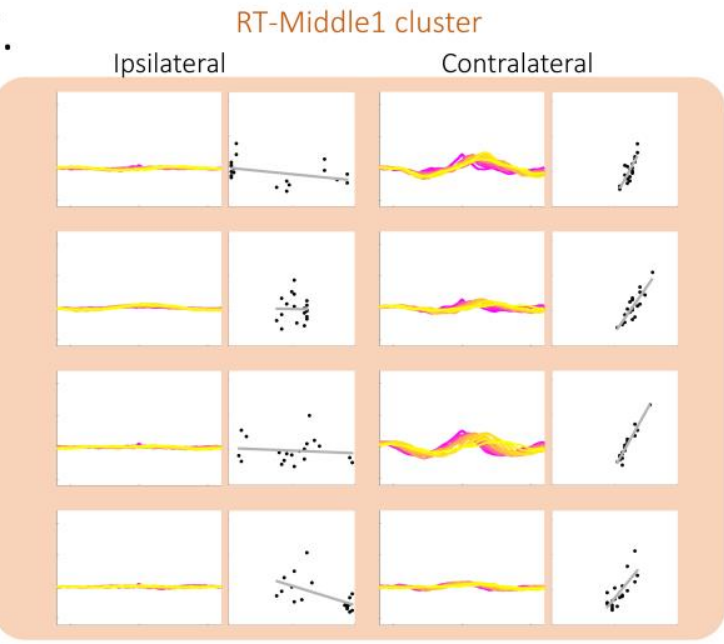

D.

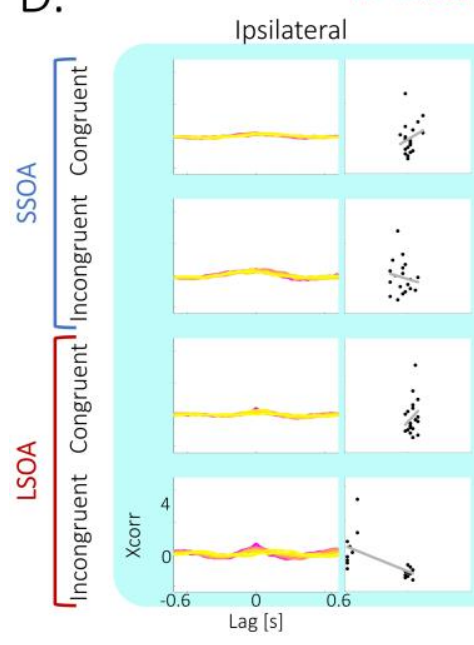

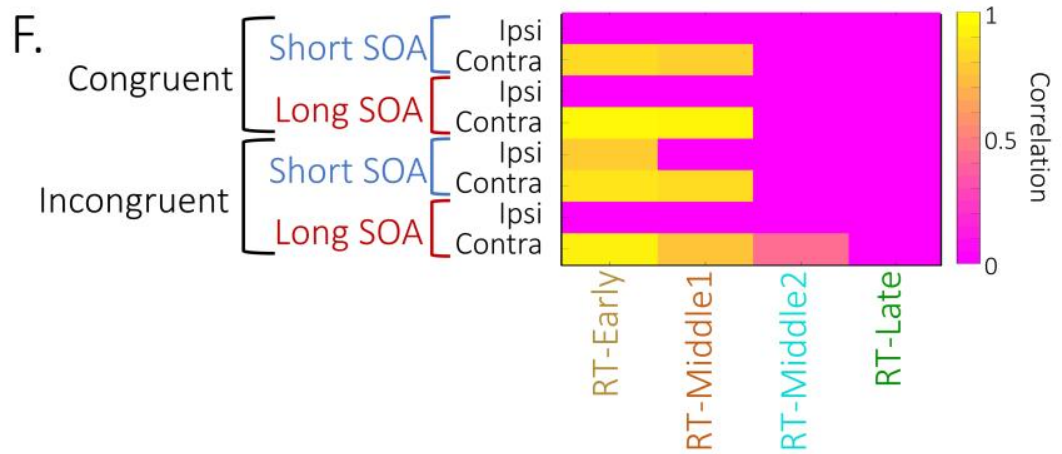

Contralateral

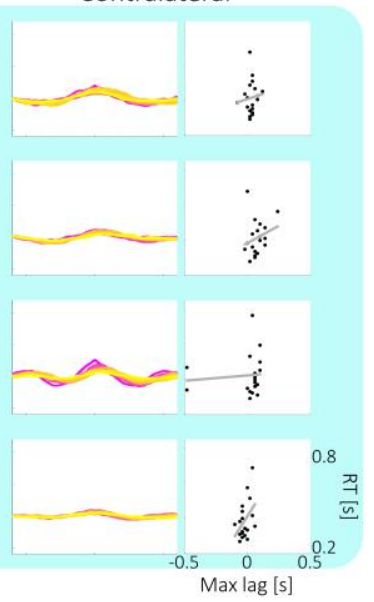

E.

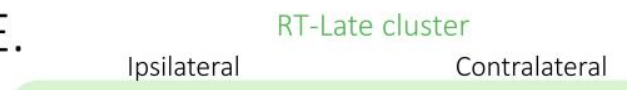

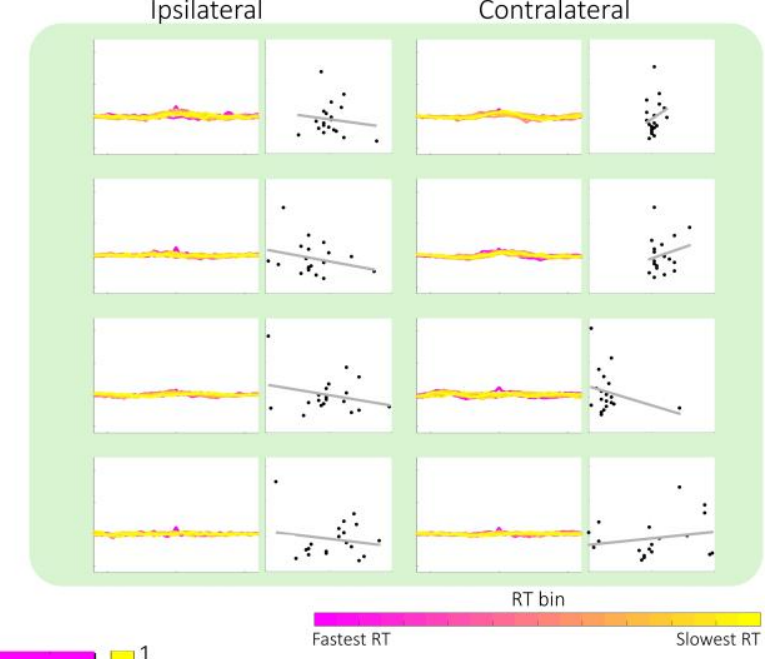


bioRxiv preprint doi: https://doi.org/10.1101/2021.01.02.425103; this version posted April 6, 2021. The copyright holder for this preprint (which was not certified by peer review) is the author/funder, who has granted bioRxiv a license to display the preprint in perpetuity. It is made available under aCC-BY-ND 4.0 International license.

Figure S5 - Correlation of cluster response-locked neural activity with visual processing. (A) Schematic illustration of the procedure for computing the cross-correlation (Xcorr) between response-locked neural activity across RT bins: Cross-correlation between response-locked activity at the fastest RT bin and all subsequent bins was computed (left; magenta lines depict mean Cue and Target onset times). If cluster activity is target-associated, maximal cross-correlation will follow the RT (here indicative of quantile's mean target-onset time), resulting in a positive shift of cross-correlation lag (middle). If cluster activity is responseassociated, maximal cross-correlation will be centered on target onset, resulting in a zero shift across all RT bins (right). Fastest bin- magenta; slowest bin-yellow. (B)-(E) Cross-correlogram of response-locked neural activity at different RT bins (pink-fastest $R T$; yellow - slowest RT) as a function of cross-correlation lag (left columns), and Pearson correlation (grey line) between maximal cross-correlation lags (Max lag) and bin's mean target onsets (right columns), across the 8 conditions (Congruent / Incongruent $X$ short-SOA / long-SOA X Ipsilateral target / contralateral target) for the RT-Early (yellow), RT-Middle1 (orange), RT-Middle2 (turquoise) and RT-Late (green) clusters. (B)-(C) RT-Early \& RT-Middle1 clusters' activity is target-associated: Cross-correlation plots are positively shifted in a spatially sensitive manner, i.e. only for contralateral targets. (D)-(E). Activity in the RT-Middle2 \& RT-Late clusters is response-associated: Cross-correlation plots show no shift. (F) Significant positive correlation between crosscorrelation maximal lag and bin mean RT in the RT-Early \& RT-Middle1 clusters: significant $(p<0.05)$ positive correlations were found mainly in these two clusters, only for contralateral targets. 


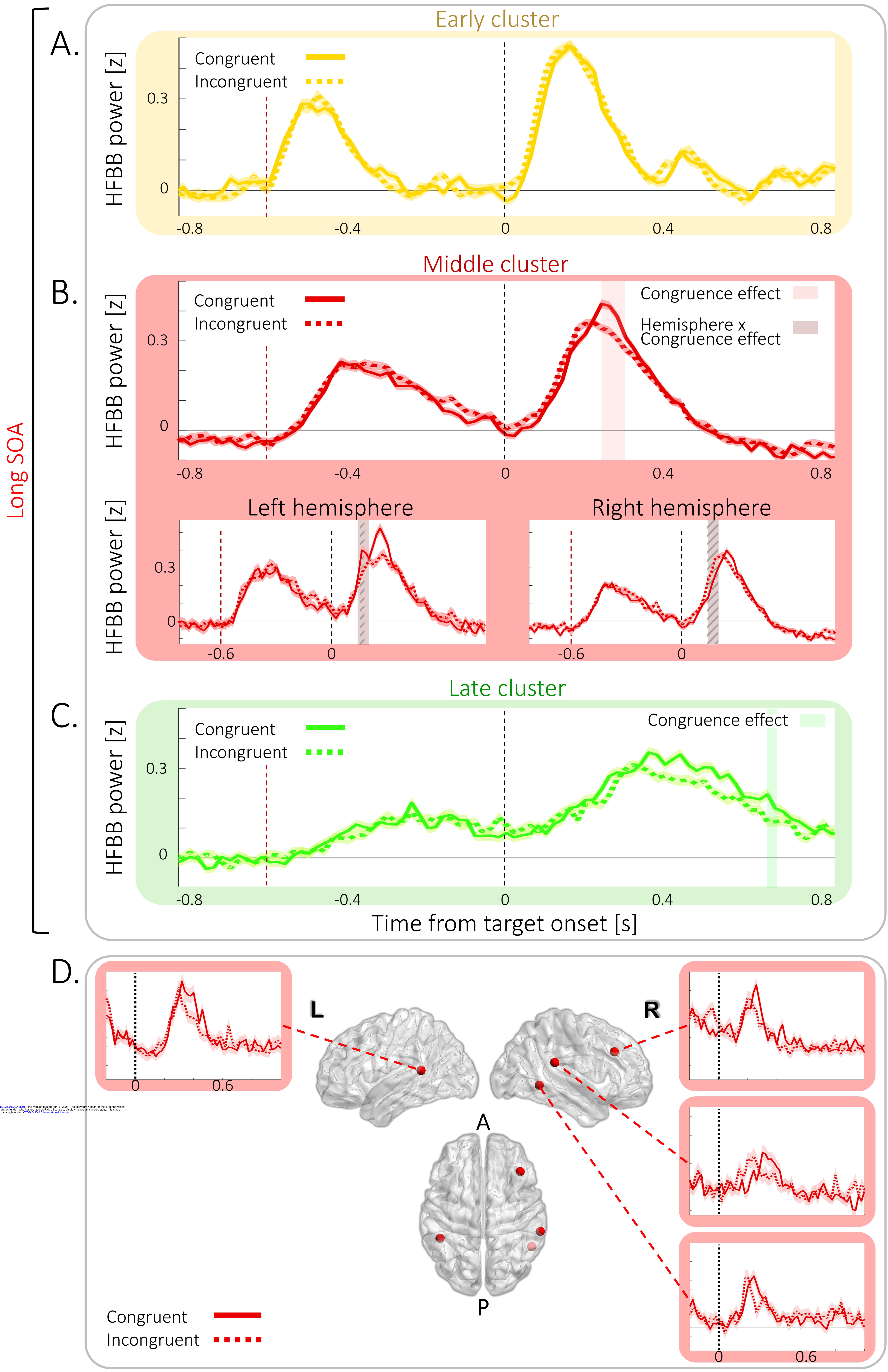


A.
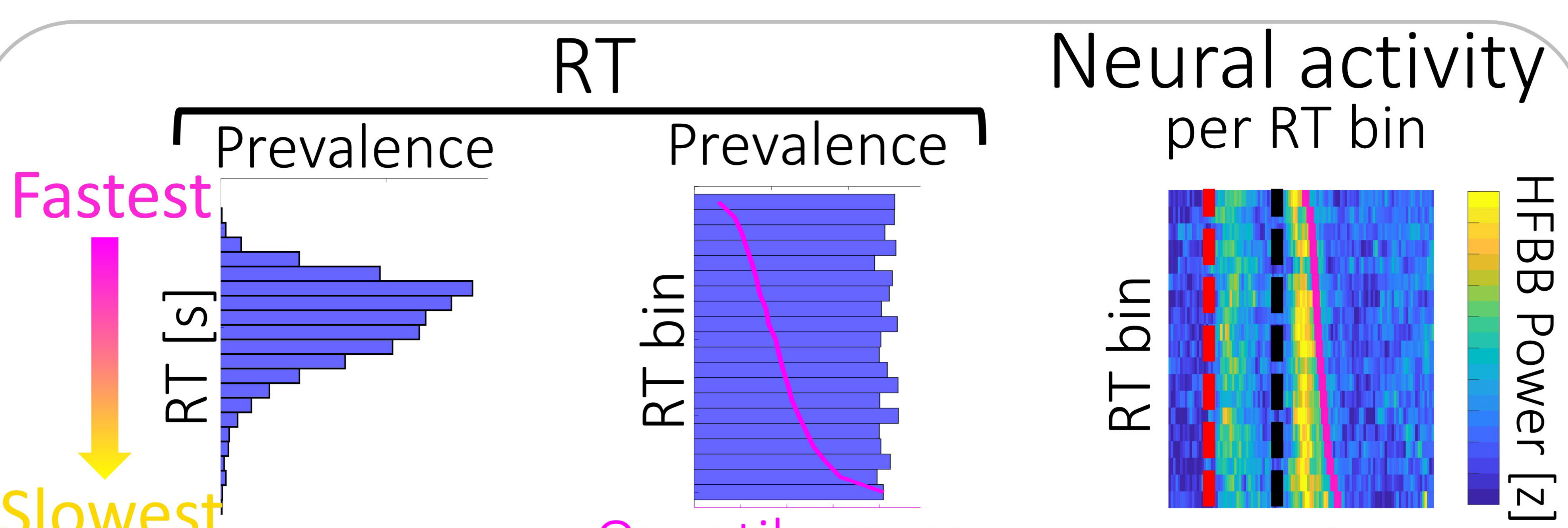

Quantile mean

$\mathrm{RT}[\mathrm{s}]$

B.

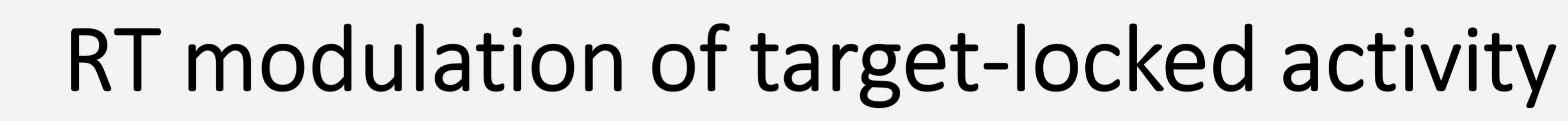

Early cluster

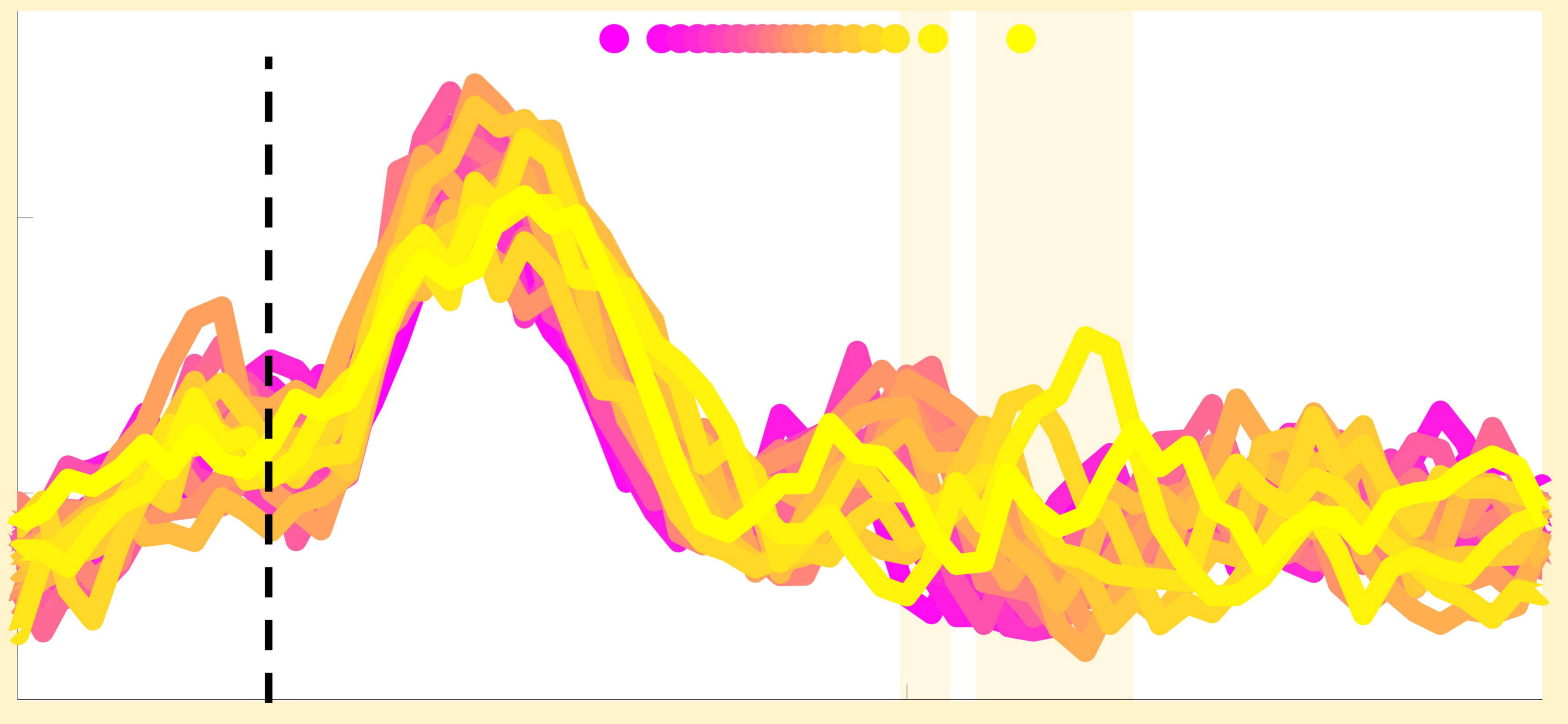

Middle cluster

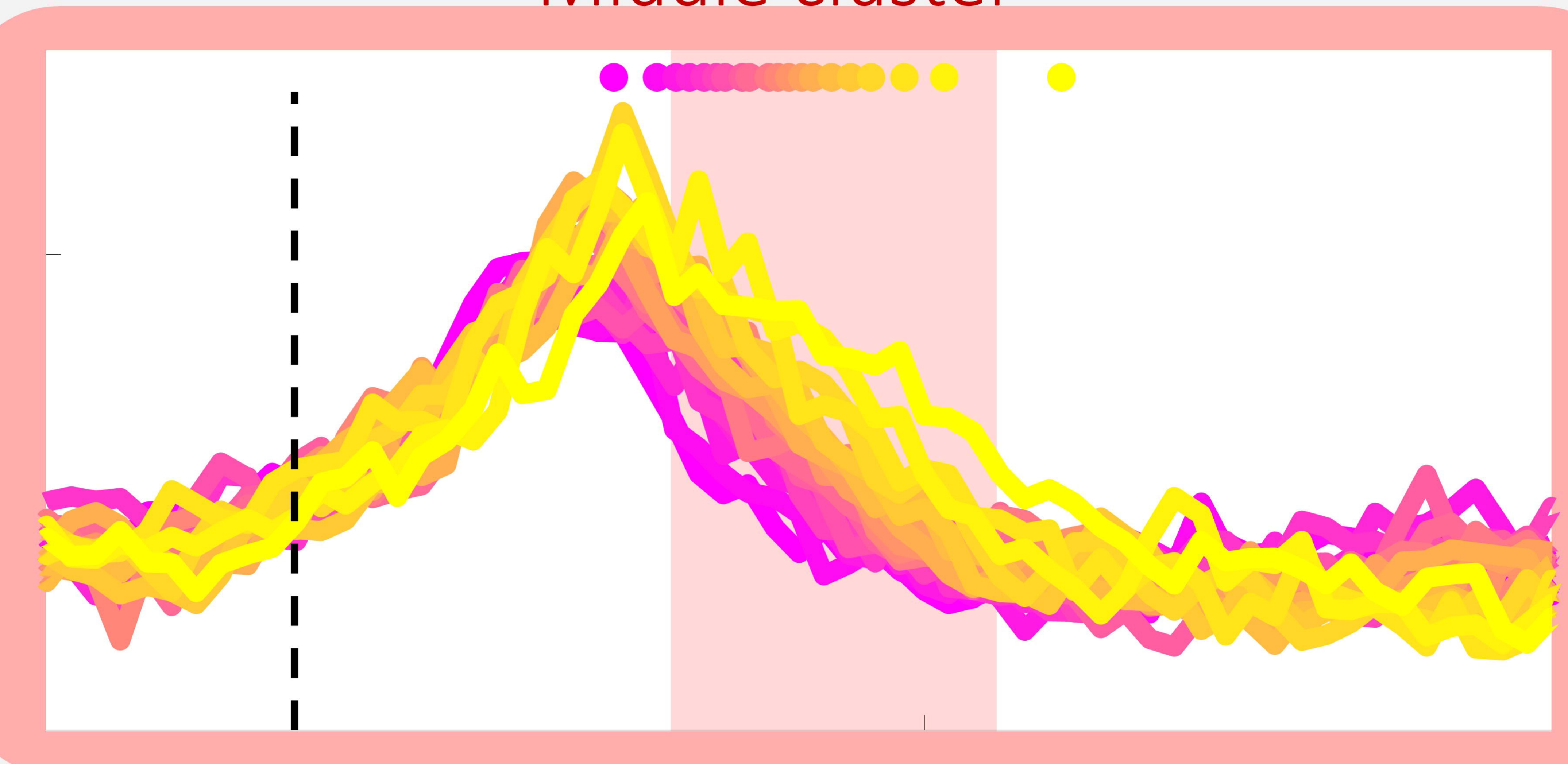

Late cluster

C

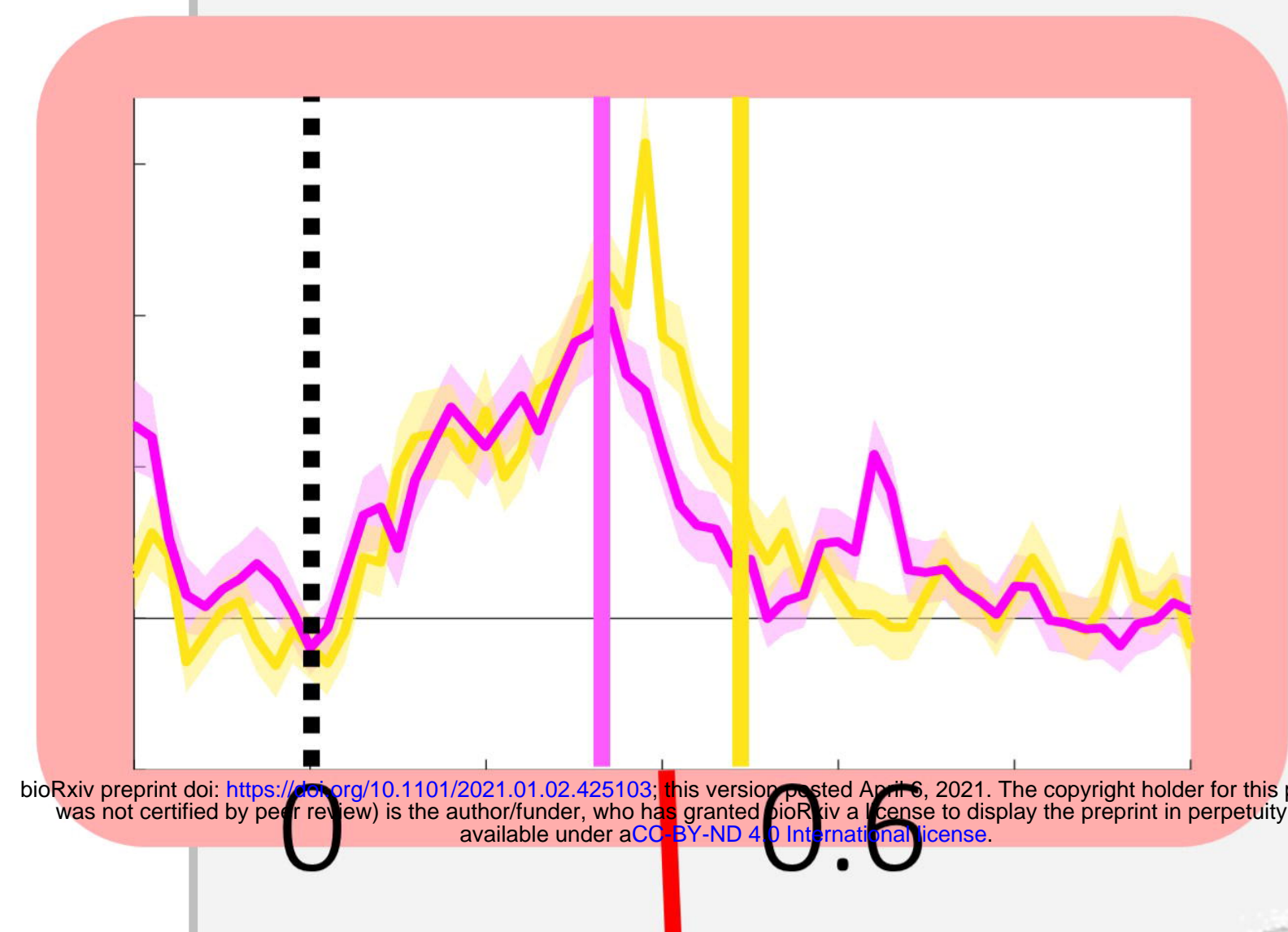

$\mathbf{L}$

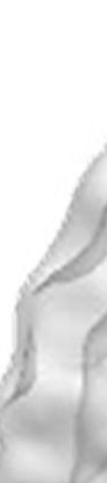

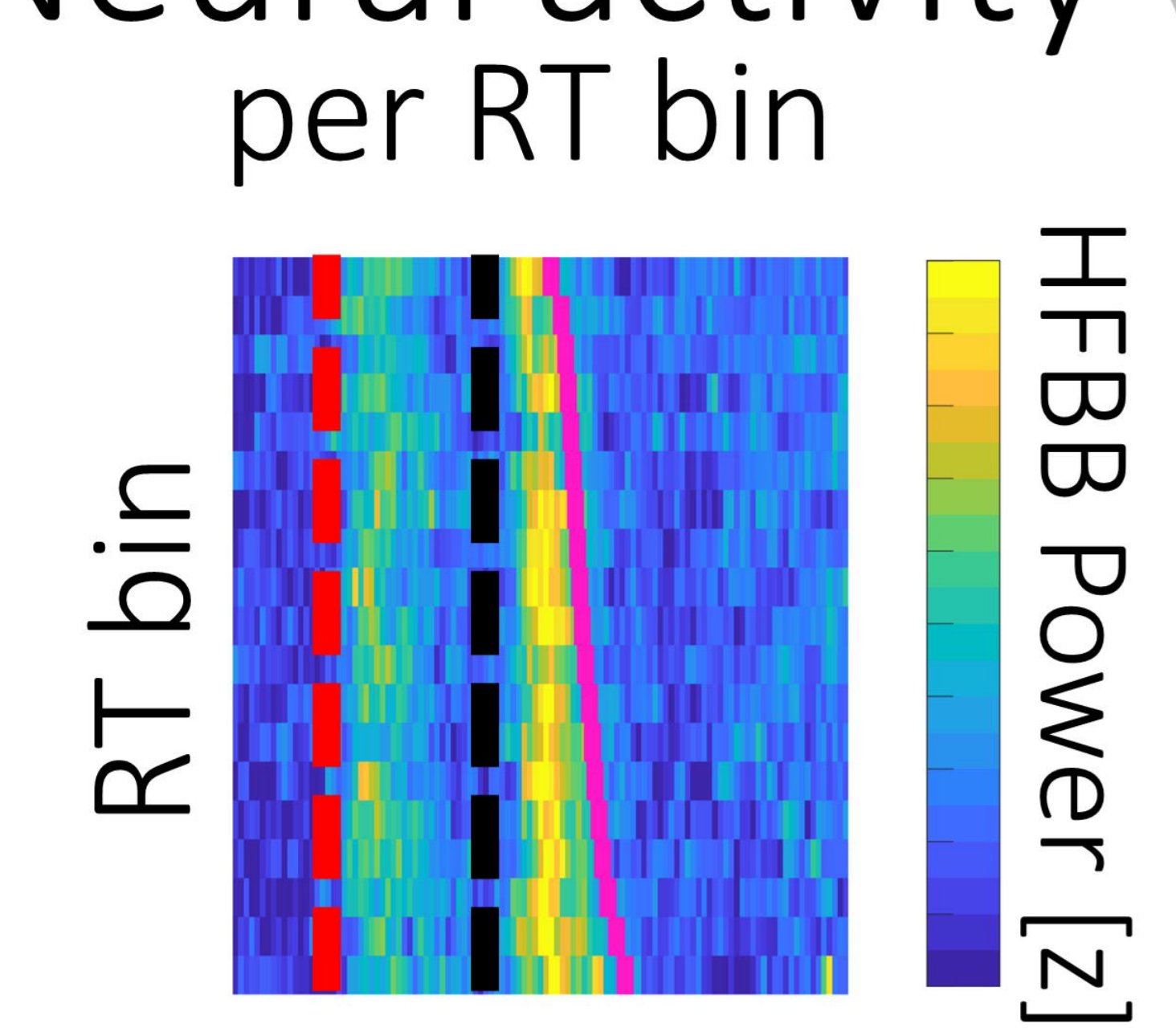

Time from target onset

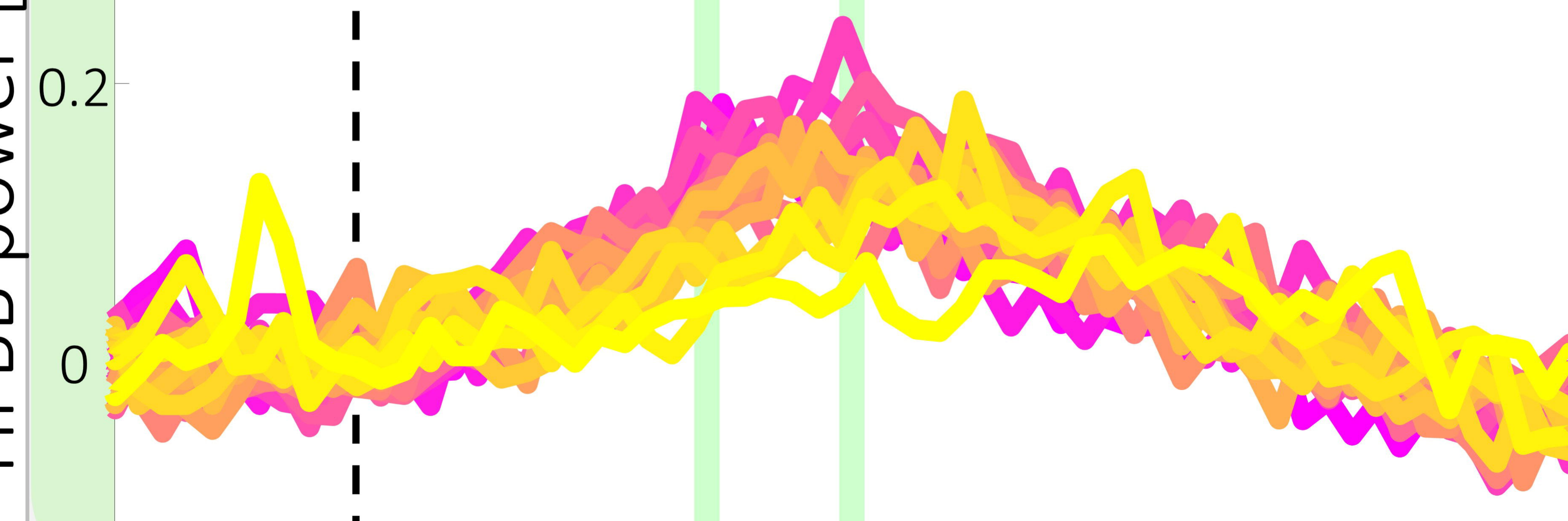

Time from target onset [s]

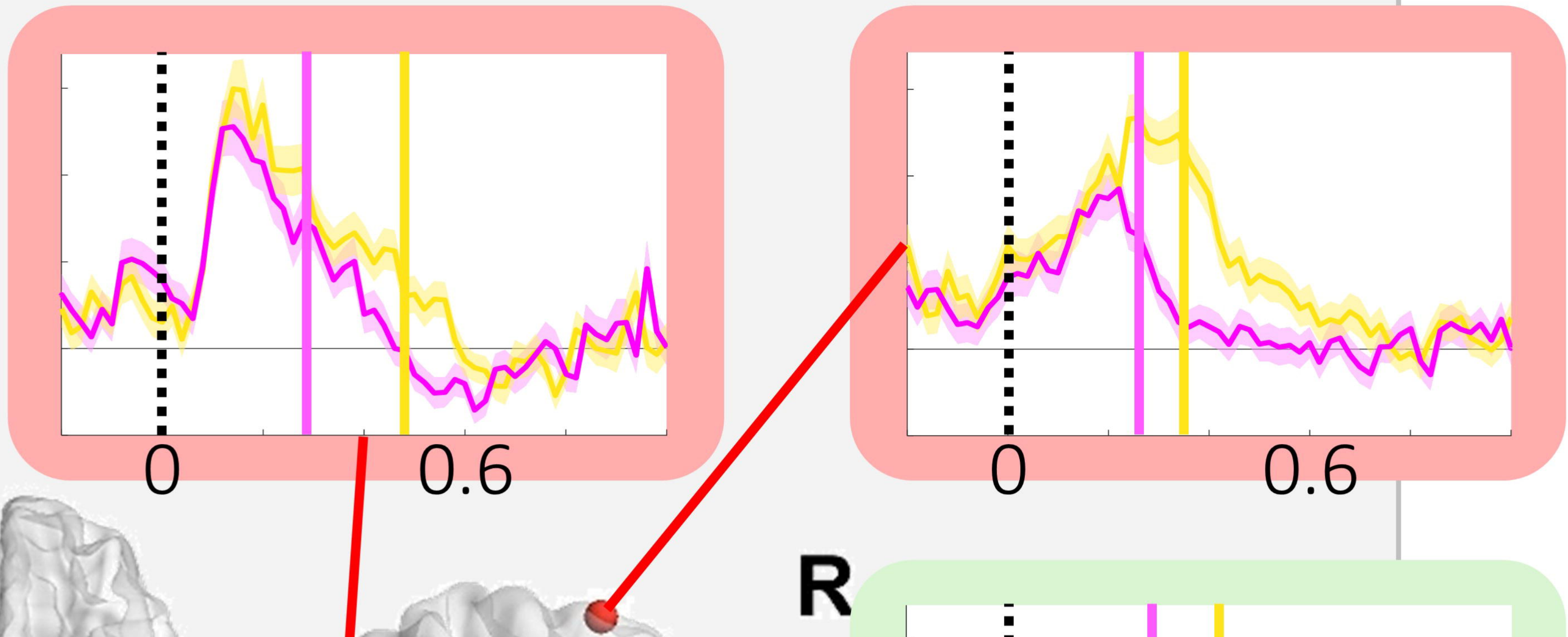

$\mathbf{R}$

D.
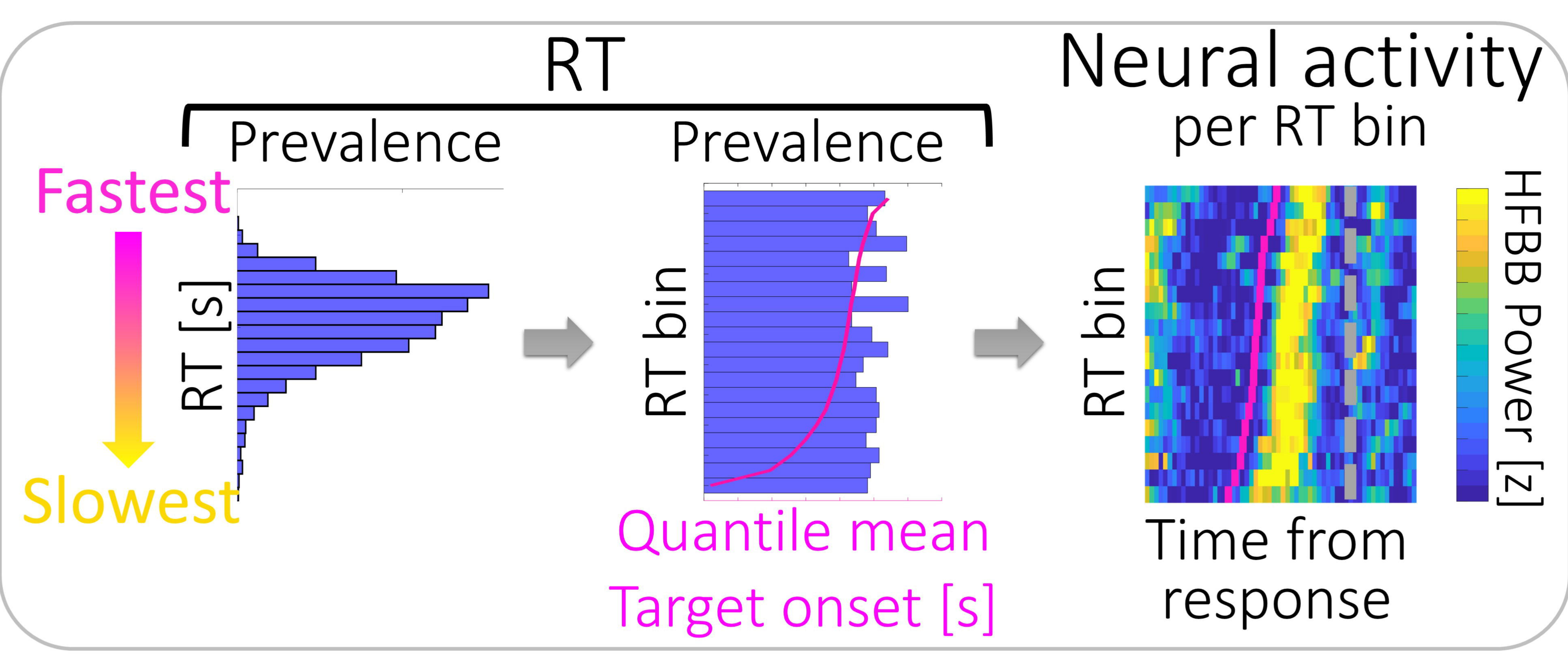

E. Visual modulation of response-locked activity RT-Early cluster
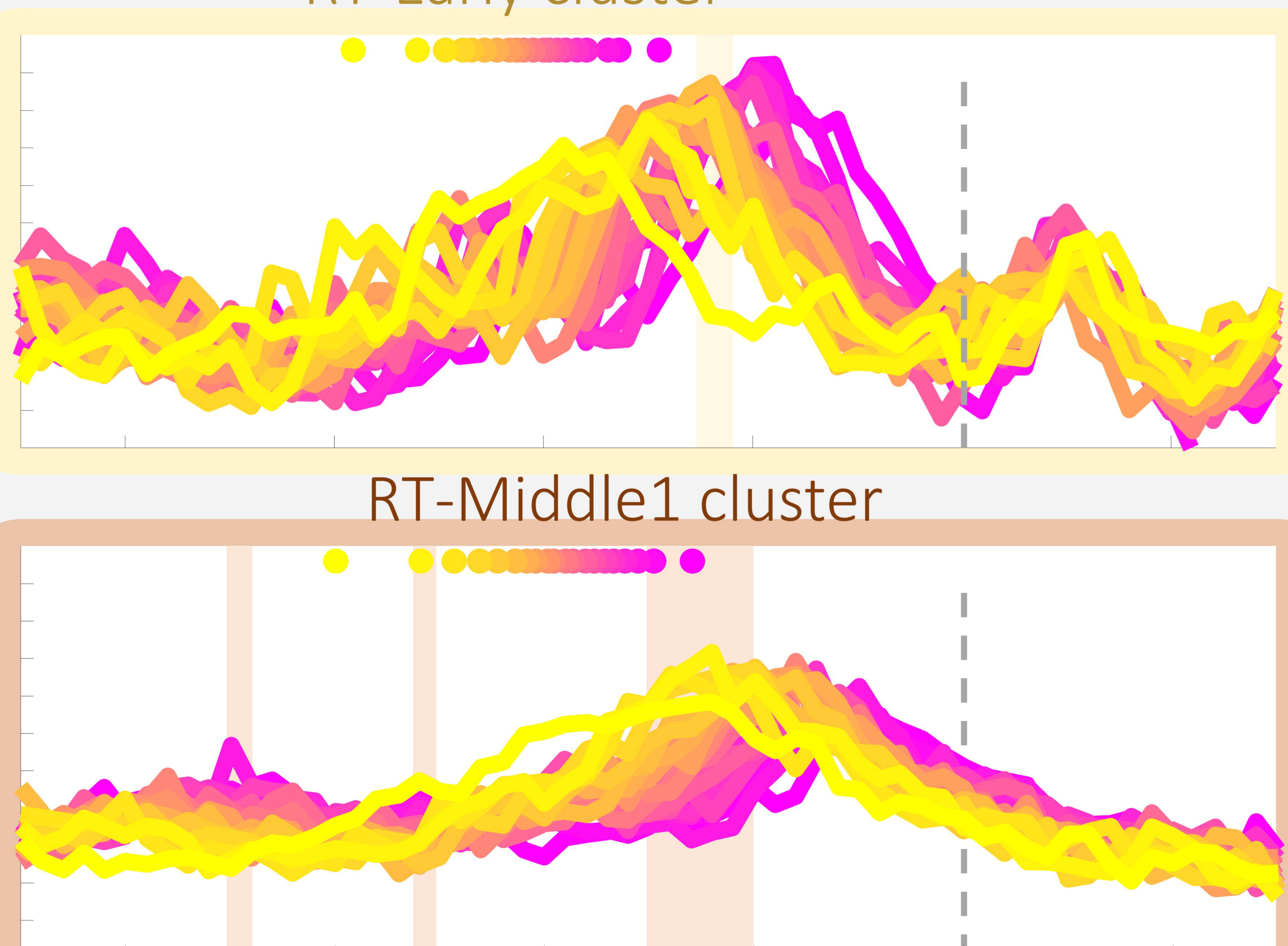

$8_{0}^{8}$

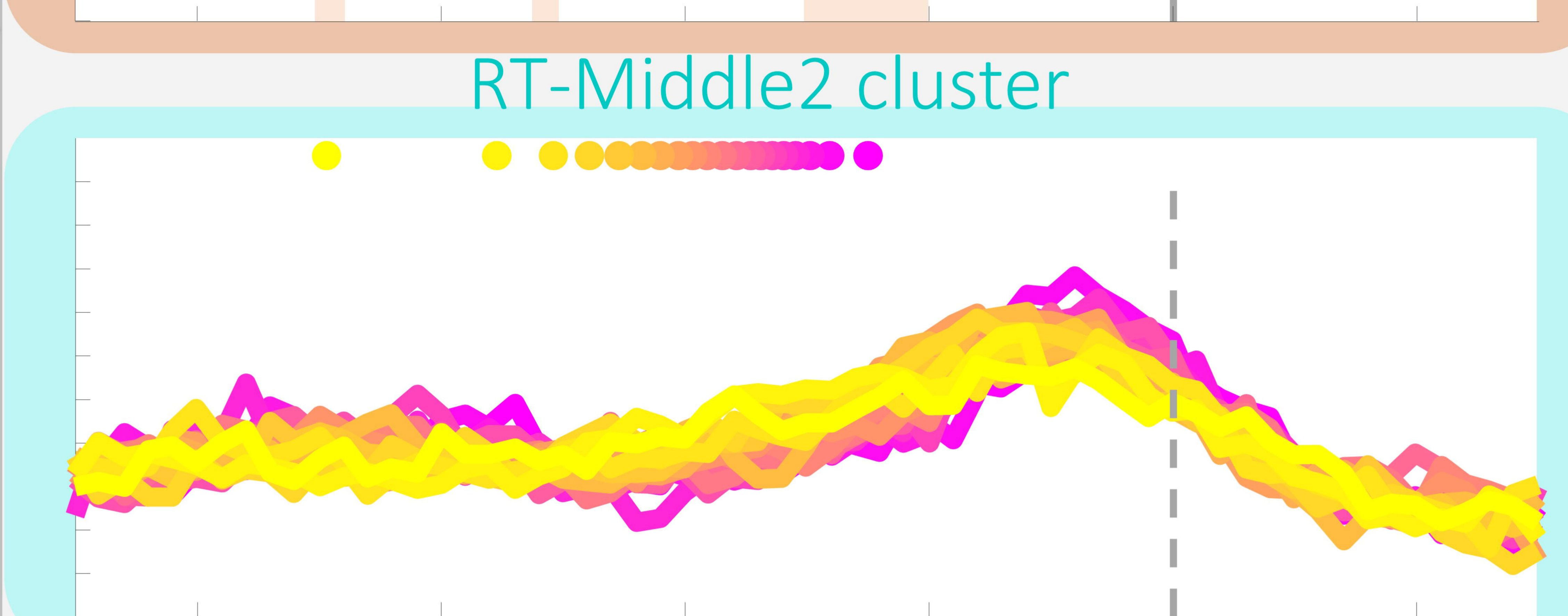

RT-Late cluster

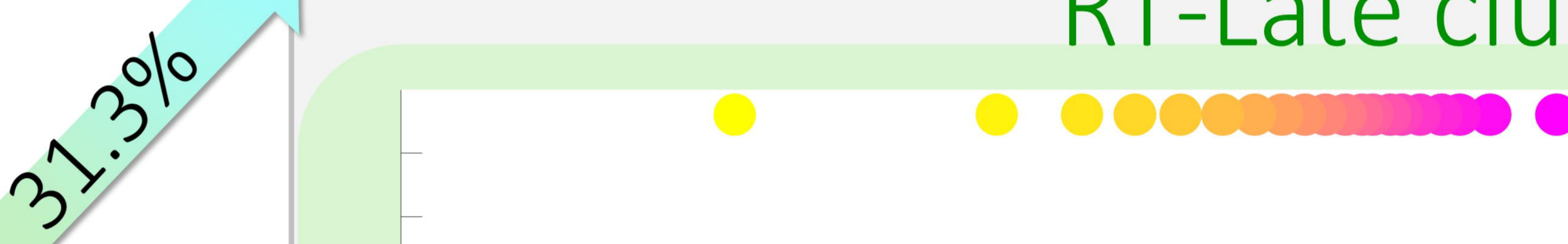

$-0.8-0.4$ Time from response [s]

Slowest RT

F.
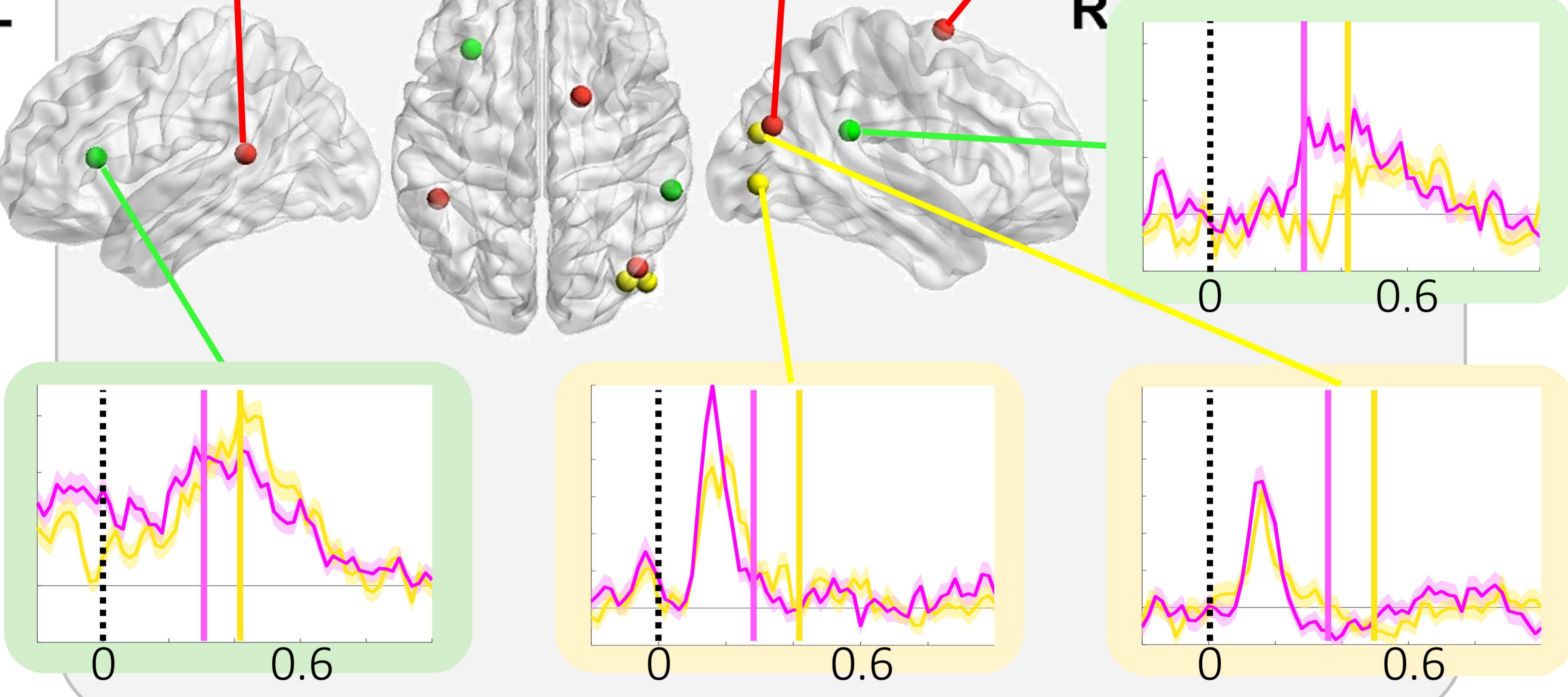

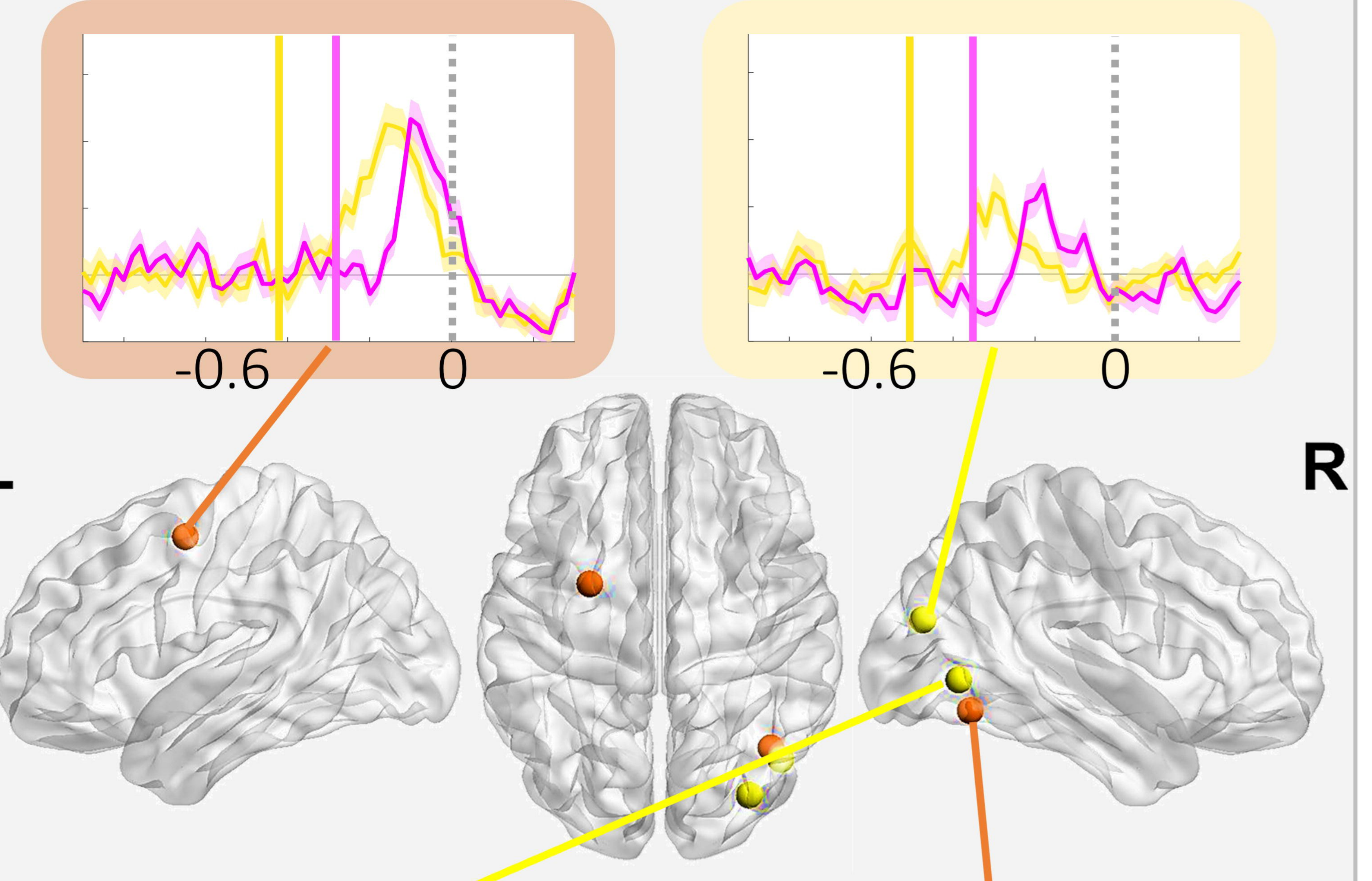

Fastest -

trials

trials
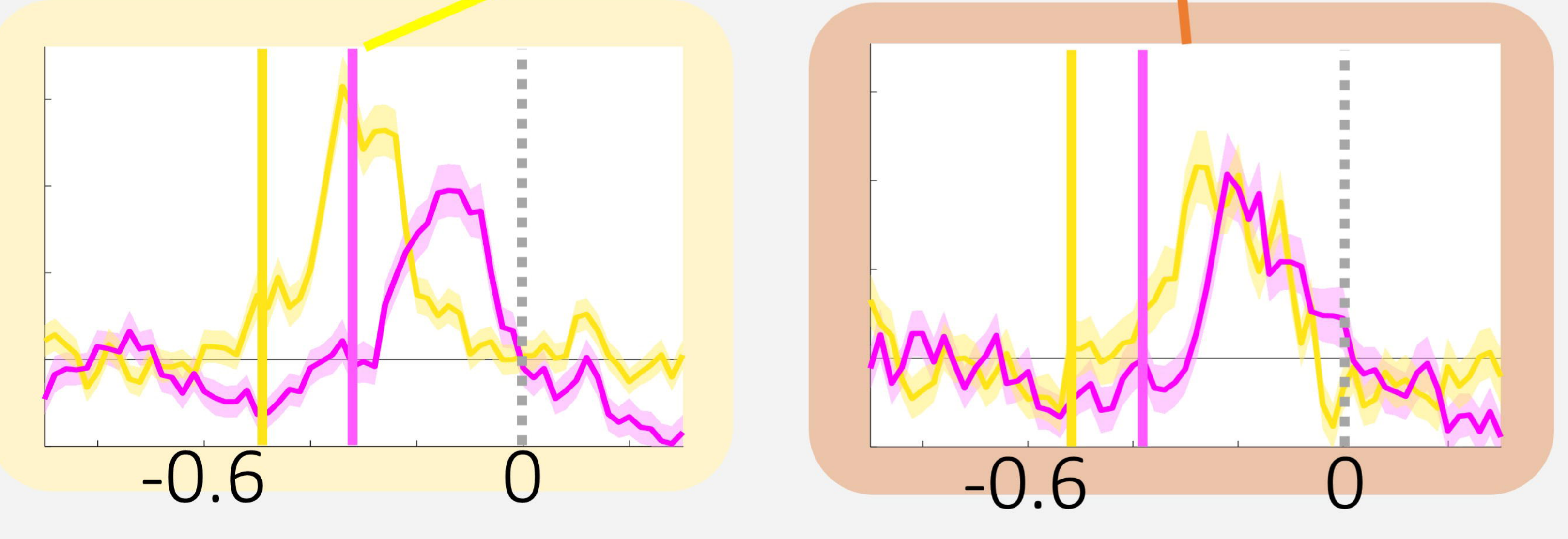


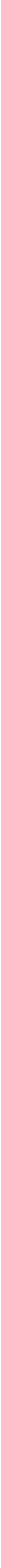

